\title{
Hipólito Rodríguez Pinilla (1860-1936) y las estrategias institucionalizadoras de la Hidrología Médica en España
}

\author{
Juan Antonio RODRÍGUEZ SÁNCHEZ ${ }^{(1)}$ \\ ${ }^{(1)}$ Área de Historia de la Ciencia. Facultad de Medicina. Universidad de Salamanca \\ jarshm@usal.es
}

\begin{abstract}
Resumen
Hipólito Rodríguez Pinilla fue, a partir de 1913, el primer profesor que ocupó la cátedra de la asignatura de Hidrología Médica, creada como de libre elección en el período de doctorado en la Universidad Central de Madrid, única en España en la que podía alcanzarse esta graduación. Como miembro del Cuerpo de Médicos de Baños desempeñó la dirección de diversos balnearios desde 1887 hasta su jubilación en 1933, de lo que dejó constancia en memorias y monografías. Desde la cátedra y la Real Academia Nacional de Medicina, a la que ingresó en 1924, difundió los conocimientos científicos sobre las aguas mineromedicinales y la climatología entre profesionales de la medicina y sociedad en general. Su convicción de la necesidad de promover la investigación y especialización, fines para los que consideraba obsoletas las instituciones existentes, lo hizo artífice de la supresión del Cuerpo de Médicos de Baños.
\end{abstract}

Palabras clave: Rodríguez Pinilla, Hidrología Médica, Institucionalización, Especialidades Médicas, Política Sanitaria, Médicos de Baños, Cátedras de Universidad, Empresa Balnearia, Sociedades Científicas, Revistas Médicas

Hipólito Rodríguez Pinilla (1860-1936) and the strategies to institutionalize spanish Medical Hydrology

\begin{abstract}
Hipólito Rodríguez Pinilla became the first professor of the School of Medical Hydrology in 1913 when it was created as an optional subject for the doctorate degree in the Central University of Madrid, the only one that offered the possibility of obtaining this specialization. As a member of the Baths Doctors Body, he undertook the direction of several spas between the years 1887 and 1933 (year in which he retired) during which he wrote many monographies and put down many records. From his position in the School and in the Royal Academy of Medicine (which he reached in 1924), he extended scientific knowledge on
\end{abstract}


mineral medicinal waters and on climatology amongst medical professional and the general society. He was convinced of the need to promote investigation and specialization, both unreachable through the existing institutions, thus deciding the disintegration of the Baths Doctors Body.

Key words: Rodríguez Pinilla, Medical Hydrology, Institutionalization, Medical Specialization, Health Policies, Bath Doctors, University Schools, Spa Establishment, Scientific Society, Medical Journals

REFERENCIA NORMALIZADA

Rodríguez-Sánchez JA. Hipólito Rodríguez Pinilla (1860-1936) y las estrategias institucionalizadoras de la Hidrología Médica en España. Balnea, 2012, 7, 13-47.

\section{INTRODUCCIÓN}

Hipólito Rodríguez Pinilla fue el primer catedrático de "Hidrología Médica" asignatura de las de libre elección en el doctorado en Medicina, que se realizaba exclusivamente en la Universidad Central de Madrid. Esta singularidad justifica por sí sola la necesidad de unos apuntes biográficos que permitan comprender su papel en la creación de la cátedra y en el posterior desarrollo de la misma. Sin embargo, desde la primera aproximación a sus datos biográficos se percibe la rica complejidad de una persona vinculada a centros de poder y redes que conectaban ciencia y política en un período de profundos cambios en la historia española. Por ello sorprende aún más que sólo haya sido objeto de breves páginas en diversos repertorios biográficos, recolectoras de fechas y eventos, hagiográficas las más de las veces y plagadas de errores que demuestran que la erudición libresca no se nutre del archivo.

Esta biografía no pretende ser tal, sino una aproximación al ejercicio profesional y el conocimiento científico de las aguas mineromedicinales en España en ese período en el que Pinilla estuvo en ámbitos significativos en la toma de decisiones. El punto de partida han sido dos comunicaciones previas, aquí integradas y reformuladas $^{1-2}$, sobre lo que considero los dos acontecimientos más trascendentes para la Hidrología Médica en España y para el propio Pinilla: la creación de la cátedra y la supresión del Cuerpo de Médicos de Baños. Tal vez llame la atención este segundo aspecto, continuamente suprimido de cualquier aproximación biográfica al personaje, pero que es precisamente el que nos ofrece su auténtica dimensión como persona, con contradicciones, idearios y servidumbres.

Insisto en ello porque esa labor aún está por hacer. La producción escrita de Hipólito Rodríguez Pinilla fue ingente y no sólo la científica. Su seudónimo, $F a$ Presto, nos pone sobre aviso de que nos encontramos con un autor que escribió continuamente y publicó con idéntica asiduidad. Homeopatía, Pediatría, Patología e Hidrología Médica podrían parecer las disciplinas científicas que mayor número de 
trabajos recogieron en forma de monografías, artículos o noticias, pero no fueron las únicas y gran parte de los periódicos médicos de la época contaron con su firma. A ello habría que añadir la prensa general y política, local y nacional, siendo fundador, director y columnista de varios periódicos y revistas a lo largo de su vida. Si a ello añadimos una abundante producción epistolar, podemos concluir que nos encontramos ante una investigación por realizar y que sólo a través de ella podríamos adquirir un conocimiento real de uno de los personajes más necesarios para comprender la España científica de la Restauración a la República.

\section{LA PERSONA Y EL PERSONAJE: PINILLA ANTES DE LA CREACIÓN DE LA CÁTEDRA}

\section{Hipólito Rodríguez Bartolomé: apuntes biográficos previos}

En febrero de 1924, Concha Lizárraga, esposa de Miguel de Unamuno, recibía una carta en la que podía leer:

"Querida amiga: acabamos de conocer la noticia del destierro de D. Miguel que me ha impresionado mucho, porque me lleva mi memoria al recuerdo de mi niñez en que yo presencié en mi casa una cosa igual. También le quitaron a mi padre la catedra y le mandaron a Portugal. Entonces se apreciaban en mi casa a los pocos amigos que nos quedaban"3

Quien así se expresaba era Hipólito Rodríguez Pinilla, catedrático de Hidrología Médica en la Universidad Central, quien cuatro años antes también había compartido estos recuerdos con el propio Miguel de Unamuno: "Esto me lleva a recordar mis ocho años, mi padre en Portugal y la penuria y lagrimas en casa" ". Sin duda unos recuerdos que marcarían profundamente su posterior trayectoria política, republicana y liberal, heredera de "la Septembrina" (la revolución de 1868) de la que su padre, Tomás Rodríguez Pinilla, fue impulsor en Salamanca.

Fue en Salamanca donde nació Hipólito Rodríguez Bartolomé, el 13 de agosto de 1860, en el número cuatro de la Calle de las Muertes ${ }^{5}$. Hipólito era el menor de los siete hijos que tuvieron Tomás Rodríguez Pinilla y María Concepción Bartolomé Polo. Su madre era de Ledesma, población a la que quedaría vinculada toda la familia por diversos motivos y donde asentarían su residencia Leonor y Cándido, el famoso poeta ciego, hermanos de aquél. Su padre era abogado, Jefe Superior de Administración y había tenido cargo como Consejero de Estado y ocupado la subsecretaría de Hacienda durante el Sexenio Revolucionario ${ }^{6}$. Antes de esto había sido profesor de instituto y, más tarde, catedrático de Historia de la Geografía en la Universidad de Salamanca, cargo que ocupaba cuando, por su afiliación al partido progresista y su participación en los movimientos que condujeron a la revolución, fue desterrado a Portugal en $1866^{7-8}$. 
Aunque en lo político quedaría claramente influido por esta experiencia, en lo profesional fue su hermano mayor, Manuel, quien siguió los pasos del padre como abogado, en tanto que Hipólito optó por estudiar Medicina en Madrid, ciudad a la que se había trasladado la familia en $1868^{\circ}$. Según Reguera, cursó las carreras de Medicina y de Ciencias con las máximas calificaciones y se licenció el 21 de noviembre de 1881 con nota de sobresaliente. Se doctoró al año siguiente y se le expidió el título en $1883^{10}$. El propio Hipólito reconocía en unos apuntes autobiográficos que su verdadera pasión desde niño fue la política, pero que su desmedido interés por conocer le hubiese llevado a estudiar cualquier otra carrera, tanto Derecho como Medicina.

Figura 1 - Retrato juvenil de Hipólito Rodríguez Bartolomé

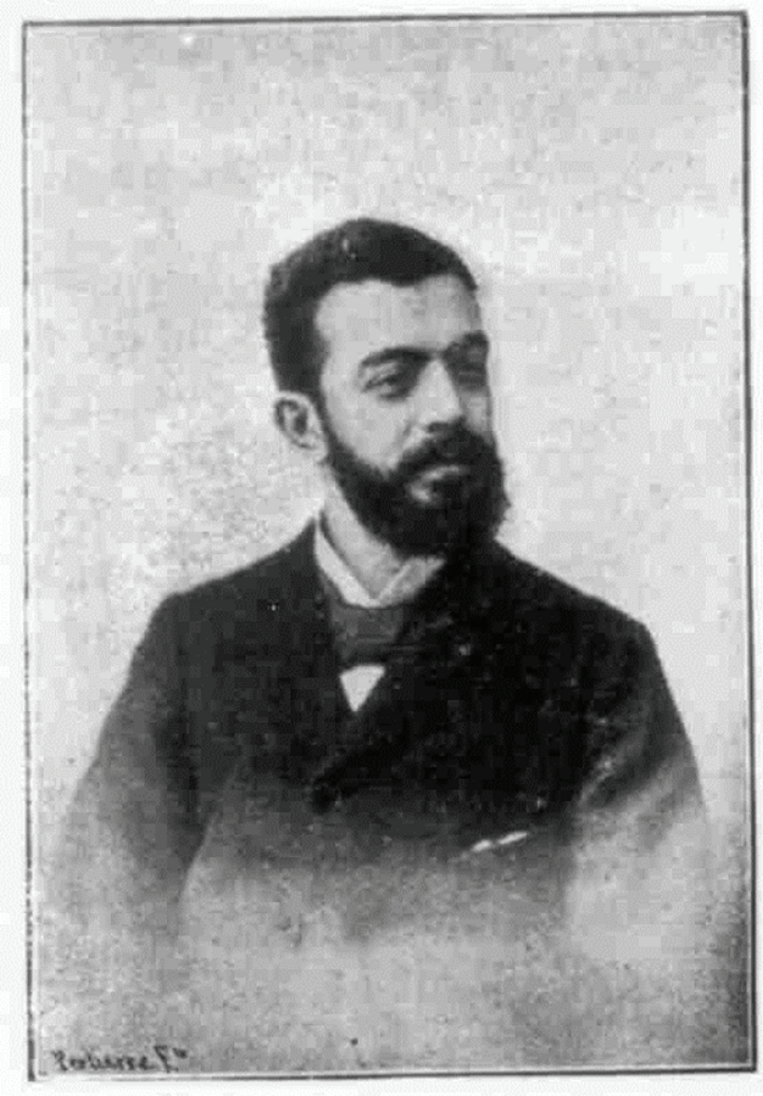


Acorde con este afán de descubrimiento y espíritu crítico, fue heredero en la clínica del escepticismo terapéutico aún vigente ${ }^{11}$, lo que propició que sus primeras experiencias profesionales las realizase en el campo de una disciplina que, en esos momentos, gozaba de popularidad entre pacientes y médicos: la homeopatía. Fue alumno del Instituto Homeopático de Madrid, premiado repetidamente, tras lo cual llegó a ser profesor del mismo y médico del Hospital Homeopático de San José, "conquistando gran clientela y siendo muy solicitada su opinión" $"$. Como miembro de la Sociedad Hahnemanniana Matritense hizo su discurso de ingreso en la sesión de 16 de noviembre de $1883^{13}$. Su labor homeopática se plasmó también en abundantes publicaciones que incluyeron la secretaría de redacción, desde 1884, de la revista El Criterio Médico (órgano de expresión de la citada Sociedad) y la simultánea participación como redactor en la recién creada Revista Hahnemanniana, que dirigida por Tomás Pellicer, era órgano oficial para el Instituto Homeopático. A mediados de 1886 desapareció definitivamente esta última y Pinilla ocupó la dirección de El Criterio Médico hasta 1888, año en que, alegando nuevas ocupaciones que le impedían encargarse, dejó la dirección pero también sus participaciones en las sesiones de la Sociedad. Dado que se había presentado en enero de ese año al car-

Figura 2 - Portada de la revista homeopática El Criterio Médico

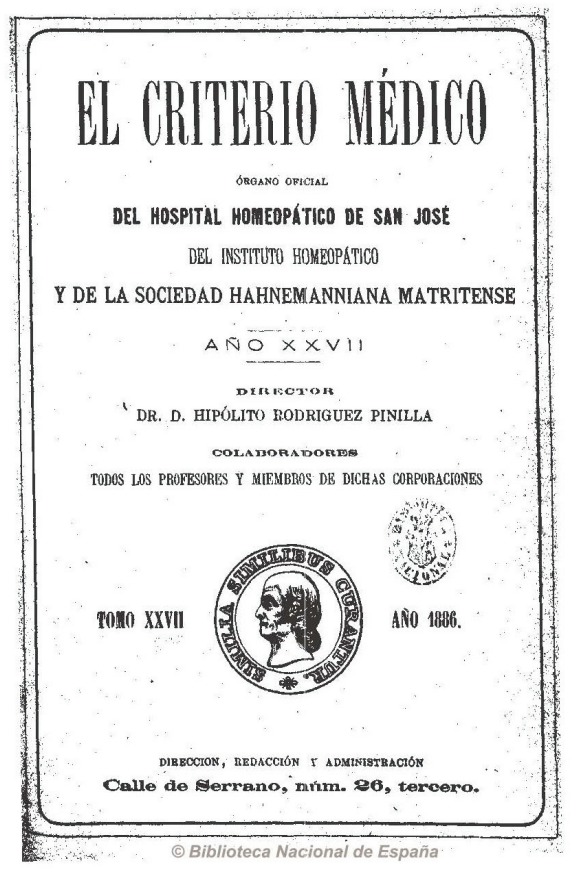


go de vicepresidente de la misma y sólo había obtenido dos votos ${ }^{14}$, cabe pensar que había más motivos para esta actitud: su defensa del positivismo científico le alejó progresivamente de la homeopatía, considerando que en ella no se estaba realizando investigación alguna a partir del legado de Hahnemann ${ }^{15}$. No obstante, su defensa de la homeopatía estuvo presente en el Congreso Hidrológico Nacional de 1888, en el que participó junto al otro gran hidrólogo homeópata, Anastasio García López ${ }^{16}$. Esta aproximación a las aguas mineromedicinales, mucho más determinante de su posterior trayectoria, se había producido por primera vez el año anterior, 1887, al ganar la oposición para formar parte como numerario del Cuerpo de MédicosDirectores de Baños, algo a lo que concederemos mayor atención en el siguiente apartado.

Como era habitual en la época, Pinilla simultaneó la atención a la Hidrología con su carrera académica. En 1901 era profesor auxiliar en la Facultad Municipal de Medicina de la Universidad Literaria de Salamanca ${ }^{17}$, facultad de las consideradas "libres", por haber sido suprimida como Facultad estatal por la célebre Ley Moyano de 1857 y pasar a depender su financiación del Ayuntamiento y la Diputación ${ }^{18}$. En ese mismo año, desde el 15 de enero, pasó a ocupar el puesto de catedrático interino de Patología Médica, pese a lo cual se presentó a la oposición para cubrir la cátedra de Clínica Médica vacante en la Universidad de Barcelona. Debemos tener presente que, sin menoscabo de la arraigada vinculación de Pinilla a Salamanca, su Facultad de Medicina no tenía en esos momentos un reconocimiento oficial y su carácter municipal auspiciaba el localismo entre el profesorado, lo que contrastaba con una tradicional percepción de la Universidad de Salamanca como fase transitoria en la carrera académica que debería coronarse con una cátedra en la Universidad Central en Madrid ${ }^{19}$.

Según se deduce de su expediente personal como profesor, existieron dos preocupaciones en esos años para Pinilla: obtener una cátedra y complementarla con carga docente que aumentase sus emolumentos, algo bastante comprensible si consideramos que, según consta en una carta de su amigo Unamuno, en 1902 tenía nueve hijos de su matrimonio con Magdalena Mata ${ }^{20}$. Pero también porque el acceso al grupo de catedráticos (sólo 32 en esos momentos) suponía su asentamiento en esa oligarquía social salmantina controladora de las instituciones ${ }^{21}$. En ese año se presentó a oposiciones a dos cátedras vacantes en Salamanca, la de Patología Médica (que ocupaba interinamente) y la de Enfermedades de la Infancia, ganando esta última y siendo nombrado catedrático de la misma el 27 de diciembre de $1902^{22-23}$, uno de los primeros en hacerlo con carácter oficial debido al nuevo estatuto legal y reconocimiento estatal de la Facultad de Medicina ${ }^{24}$. En su nombramiento como catedrático numerario se hacía constar que era con un haber anual de 3.500 pesetas, con cargo aún a los presupuestos municipales. El uno de enero de 1903 Pinilla tomaba posesión del cargo ${ }^{25}$. Sin embargo, desde 1901 figuran escritos en los que solicita hacerse cargo también de otras cátedras con carácter de acumuladas: no lo consiguió con la de Clínica Médica, pero sí lo logra en 1908 con la de Patolo- 
gía Quirúrgica con su clínica de primero, segundo y tercer curso, tras la renuncia de Rodrigo Sánchez Gómez, lo que le supuso un incremento de sus retribuciones de dos mil pesetas. Es de suponer que fueron las buenas relaciones de Pinilla, tanto con el Rector como con parte de la Facultad de Medicina, las que permitieron que pese a que Miguel Royo Gonzálvez obtuviese la cátedra de Patología Quirúrgica y solicitase la acumulada en 1910, fuese Pinilla quien siguiera disfrutándola, al menos hasta final del curso $1910-1911^{22}$.

En 1905 opositó al Cuerpo de Inspectores Provinciales de Sanidad, logrando ingresar en el mismo ${ }^{26-27}$. Como pediatra dirigió "la gota de leche" salmantina, lo que no limitó sus variados intereses por otras disciplinas y avances científicos: Granjel lo presenta como defensor de la nueva técnica diagnóstica radiológica (que transmitió a Filiberto Villalobos $)^{28}$ y las cartas a Unamuno hablan de permisos para viajar al extranjero o le envía postales desde países en los que aprovecha algunas vacaciones universitarias para acudir a centros de investigación (Figura 3). Sirva de ejemplo la carta que en agosto de 1910 le envió desde San Hilario Sacalm:

Figura 3 - Tarjeta postal enviada a Unamuno desde Berlín (CMU, 38/37, 13)

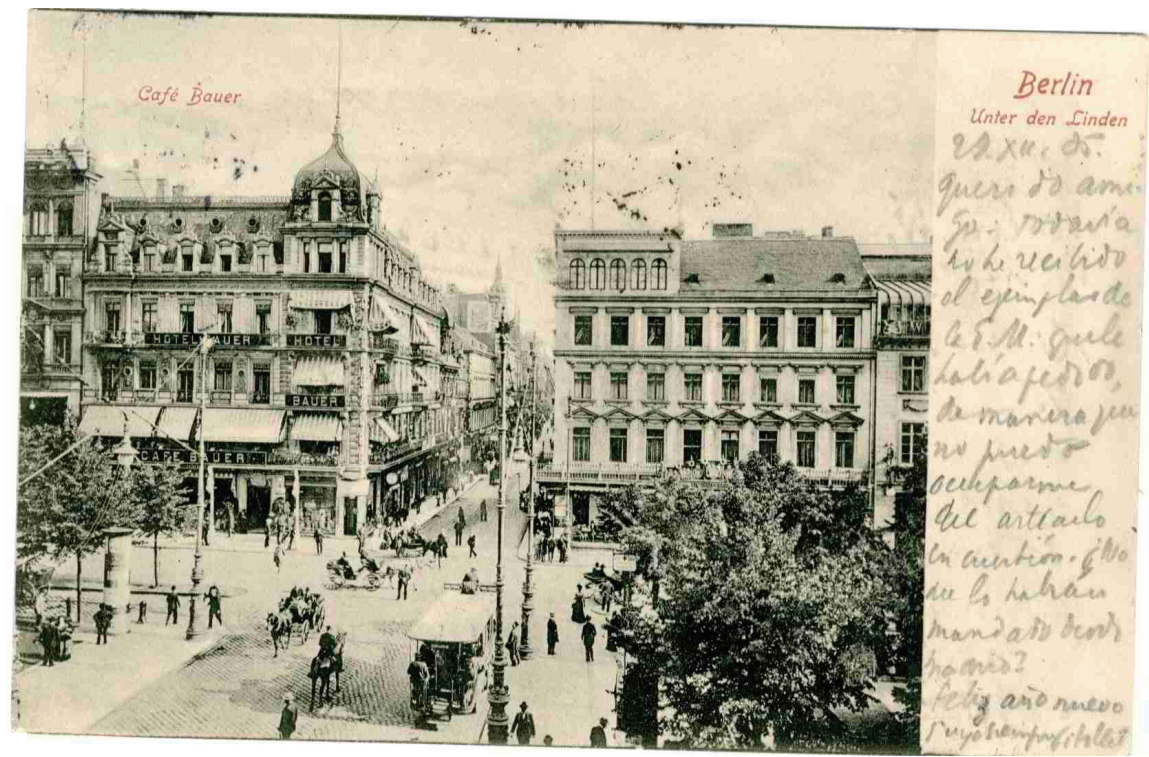

"Querido amigo: aunque sin papel sellado, voy á pedirle á V. oficialmente un servicio. Está llamando poderosamente la atención del mundo científico el descubrimiento que acaba de realizar Erlich: la curación de la sifilis eficaz y rapidísima. Las estadísticas en Rusia, en Alemania ya demuestran que la cosa es seria y asombrosa. / [v.] Yo quiero ir con mi hijo Tomás á Francfort-sur-Maine, al Laboratorio Erlich" 29 
En contraposición, el claustro salmantino y sus debates, pese a los graves momentos que se vivieron, debieron resultarle mucho menos estimulantes, pues, siendo claustral, de los quince claustros celebrados y recogidos en actas sólo consta que acudiese a nueve y sólo se recogen intervenciones suyas en tres de ellos con comentarios vagos y nada comprometedores, como apoyar la propuesta ministerial de establecer relación con otras universidades y especialmente las americanas. Por otra parte, la única votación a la que se sometió para formar parte de una comisión nos lo presenta como uno de los menos populares entre los claustrales ${ }^{30}$.

En este período de vida salmantina Pinilla desarrolló también una viva actividad política y periodística. Su hermano Cándido fundó en 1904 periódicos regeneracionistas como El Castellano y El Diario ${ }^{31}$, en los que Hipólito no dejó de publicar; así como en otros de carácter progresista. Fue asiduo en las páginas del diario El Adelanto, propiedad del impresor republicano Francisco Núñez ${ }^{32}$, y cuando en 1901 apareció La Unión Escolar, portavoz de la organización homónima que presidía su discípulo y, más tarde, correligionario y amigo Filiberto Villalobos, también escribiría para sus páginas ${ }^{33}$. Las publicaciones muestran el posicionamiento político y activismo de Pinilla que le llevaron a ser representante republicano en el Ayuntamiento de Salamanca ${ }^{34}$ y vicepresidente de la Agrupación Republicana Gubernamental, constituida en Salamanca en 1910 por un grupo de intelectuales y considerada precedente del Partido Reformista de Melquiades Álvarez ${ }^{35}$, entre cuyos miembros se contó Pinilla desde su creación en $1912^{36}$ y lo que motivó que entrase a formar parte como miembro de la Junta Nacional Reformista el 29 de abril de $1914^{35}$.

\section{Hipólito Rodríguez Bartolomé: un médico de baños y su contexto antes de 1913}

En 1887 Pinilla se presentó a las oposiciones convocadas para cubrir 13 plazas vacantes en el Cuerpo de Médicos-Directores de Baños. El cargo de médicodirector de balneario era un atractivo puesto que suponía un trabajo estacional que, en el mejor de los casos, generaba ingresos para todo el año si el balneario gozaba de un abundante número de agüistas, pues desde 1868 no contaban con sueldo del Estado y sólo percibían el importe de cada consulta. Para ejercerlo era preciso ingresar por oposición en ese Cuerpo. Sin embargo, los problemas se derivaban de su estructuración a través de un escalafón de antigüedad en el que los miembros más veteranos eran los primeros en elegir destino, quedando para los últimos escasas posibilidades entre los balnearios con menor concurrencia ${ }^{37}$. Fueron muchos los médicos que consideraron que sólo era cuestión de paciencia el ascender en el escalafón y optar a la dirección de los mejores balnearios ${ }^{38}$, por lo que la demanda de ingreso en el Cuerpo siguió aumentando hasta el punto de que un Real Decreto de once de noviembre de 1879 suspendió las oposiciones a fin de limitar la entrada y fijó en cien las plazas de médicos-directores que debían componerlo. El R.D. de 25 de enero de 1887 convocó sólo 13 plazas que habían quedado vacantes en esos 
años, pero la presión de los médicos generales que deseaban ingresar fue tan intensa que debieron crear 24 plazas suplementarias, por R.D. de 5 de julio, de lo que denominaron Médicos-Directores Supernumerarios.

El tribunal para esas esperadas oposiciones estuvo integrado por renombrados profesionales, algunos de los cuales habrían de jugar un importante papel en el futuro de Pinilla: Anastasio García López, Marcial Taboada de la Riva, Isidro Casulleras y Galiana (más tarde sustituido, debido a su renuncia, por Amós Calderón y Martínez), Joaquín Eduardo Gurucharri y Echauri, Aurelio Enríquez y González, Leopoldo Martínez Reguera y Benito Avilés y Merino. Tras los tres ejercicios reglamentarios, para los que se habían inscrito 141 candidatos, Hipólito Rodríguez Pinilla fue propuesto como sexto candidato para una plaza como numerario en el escalafón.

Su primer destino fue en Caldes de Malavella, a los que se fueron sucediendo los balnearios de Arteixo (1888-1889), Caldes de Reis (1890), Calzadilla del Campo (1891-1893), Incio (1894), El Molar (1895), Fuente Caliente (Miranda de Ebro, 19011903), Zaldívar (1904), San Hilario Sacalm (1909,1910), Molinar de Carranza (1911), Ledesma (1908, 1914-1917), Sobrón y Soportilla (1918-1921), Alceda y Ontaneda (1924-1925) y Caldas de Oviedo (1926-1932). Los frecuentes cambios de balneario están acordes con su ascenso en el escalafón y, fundamentalmente, la elección de los de mayor concurrencia que, sólo con la plaza de Caldas de Oviedo, llegó a ser mayor de dos mil agüistas por temporada. Esta búsqueda, común a la mayor parte de los médicos de baños, es expresada con humor por Pinilla en una carta que, desde Zaldívar dirige en 1904 a Unamuno: "Me gusta y va sentándome bien esta su tierra. Solo me hacen falta mil bañistas para que acabe de complacerme" ${ }^{, 39}$.

$\mathrm{Su}$ labor como médico-director recondujo también su producción científica, que no se limitó a las preceptivas memorias anuales sobre los balnearios, sino que rápidamente se encaminaron a la búsqueda de una sistematización de los conocimientos existentes sobre Hidrología Médica. En agosto de 1902, desde el balneario de Fuente Caliente, escribía a su amigo Unamuno: "cien enfermos en doce dias han entrado aquí, y Alhama encargándome artículos y un viaje á Vitoria como corresponsal fotográfico y el dichoso Manual de Hidrología á quien ahora le faltan paginas". El Manual ${ }^{40}$ coronaba una labor que ya había sido reconocida oficialmente, al enviarle en 1896, junto a Manuel Manzaneque, como Delegado Médico del Gobierno de España al Congreso de Hidrología, Climatología y Geología de Clermont-Ferrant (Francia) ${ }^{41}$.

Esta labor didáctica y divulgadora muestra una necesidad de conocimientos sobre la disciplina, pues la Hidrología era estudiada en la licenciatura de Medicina desde 1866 en la asignatura "Ampliación de la Terapéutica y Farmacología. Hidrología Médica"42, si bien esto resultaba insuficiente según el criterio de los médicos de baños y causa de que los demás facultativos no contemplasen las posibilidades del remedio hidromineral. De hecho, la docencia no oficial se limitó a los cursos libres impartidos por el propio Pinilla a fin de siglo en Madrid, primer intento de 
independizar la materia ${ }^{43}$. La necesidad de mejorar la formación hidrológica de los médicos era evidente y las propuestas de soluciones no tardaron en aparecer, pese a lo cual no es posible considerar que la creación de una cátedra de Hidrología Médica partiese de presupuestos científicos o de dar respuesta a necesidades sociales.

\section{LA CÁTEDRA DE HIDROLOGÍA MÉDICA}

\section{El balnearismo español a principios del siglo $\mathrm{XX}$}

Queda expuesto que no fue la búsqueda de una mejor formación de los médicos de baños el único motivo para crear la cátedra. El balneario era y es una institución que trasciende lo asistencial y terapéutico para convertirse en ocio e industria y es por este motivo que debemos considerar las necesidades de todos los grupos sociales relacionados con el agua minero-medicinal, desde los usuarios (agüistas o bañistas) a los empresarios, desde los médicos de baños a los médicos generales, para así poder comprender a qué obedeció esta institucionalización de la disciplina hidrológica $^{44}$.

La terapéutica balnearia perdía adeptos entre los enfermos y la concurrencia a estos establecimientos mostró un claro y constante descenso desde finales del siglo XIX. Las estadísticas de concurrencia obtenidas de las memorias administrativas anuales presentadas por los médicos directores de los balnearios muestran la continua disminución del número de agüistas usuarios de los establecimientos españoles: en 1901 se consideraba que sólo un $0,47 \%$ de la población española acudía a los balnearios, del cual algo menos de un tercio era de menesterosos que acudían con cargo a sus municipios ${ }^{1}$.

Para algunos médicos el problema residía en la moda que llevaba a los bañistas a centros extranjeros, pero es difícil creer que el volumen escaso de agüistas que podían permitirse el turismo termal internacional fuese el que afectaba de esa forma a la industria nacional. Para otros era el falseamiento en las estadísticas y la existencia de balnearios clandestinos ${ }^{45-46-47-48}$. La crisis económica tras el 98, la primacía de lo lúdico sobre lo terapéutico y la consecuente preferencia de la costa frente a las vacaciones en balnearios de interior y la progresiva incorporación de una terapéutica farmacológica más efectiva parecen los principales elementos que motivaron este descenso de casi 18000 agüistas en una década ${ }^{49-50}$.

Los principales afectados por esta situación fueron los empresarios, lo que incrementó su rebeldía hacia una situación que consideraban injusta. Desde la publicación del primer Reglamento de Baños en 1817 los propietarios de establecimientos balnearios consideraron vulnerados sus intereses económicos por la presencia, impuesta por el Gobierno, de un médico de baños con amplias atribuciones para decidir sobre mejoras en las instalaciones, amparada la legislación en el derecho del Estado sobre un bien público como las aguas minero-medicinales y, por tanto, su 
intervención en el control de la explotación. Los empresarios alegaban como principal perjuicio para su industria el hecho de que el escalafón de antigüedad implicaba que los médicos que ocupaban los mejores y más concurridos balnearios eran los más ancianos; mientras que los pequeños establecimientos sólo eran lugar de paso para los más jóvenes, algo poco grato a los clientes ${ }^{51}$. Solicitaban así la libertad para contratar a los médicos que ellos mismos eligiesen. A tal fin comenzaron a aunar sus esfuerzos a favor de la que dieron en llamar "libertad balnearia", fruto de los cuales surgió en 1871 la Asociación Nacional de la Propiedad Balnearia. No obstante, fue a principios del siglo XX cuando este organismo se reorganizó como Asociación de Propietarios de Balnearios y Manantiales de Aguas Mineromedicinales, como consecuencia de la Asamblea General de Propietarios celebrada el 15 y 16 de febrero de 1905, auspiciada por los cambios que se anunciaban en la Instrucción de Sanidad $^{52}$.

Los intentos del Estado para conciliar los intereses de ambos grupos desembocaron en la creación en 1903 del Cuerpo de Médicos de Baños Habilitados, independiente del ya existente, y entre cuyos componentes podrían escoger los propietarios de establecimientos no ocupados por médicos directores; medias tintas que emborronaron aún más el confuso panorama ${ }^{53}$.

La clase médica en general también mantenía una actitud poco propicia hacia los Médicos de Baños: "Los compañeros de profesión nos miran como los antipáticos monopolizadores de una rama de la terapéutica; [...]", escribía en 1904 el médico director de Buyeres de Nava (Asturias), Arturo Alvarez Buylla ${ }^{54}$. Efectivamente, la reclamación de los médicos generales a fin de que se reconociese su capacidad para recetar aguas minerales (del mismo modo en que lo hacían con cualquier otro específico) se vio sólo satisfecha en parte por el Reglamento de Baños de 1868, dónde se reconocía esta capacidad a cualquier médico de la localidad de los baños, con lo que creaba la figura del médico libre, si bien esta prescripción debía ser refrendada por la firma del Médico Director de Baños ${ }^{53}$. La Instrucción General de 1904 ampliaba este derecho a todo médico en ejercicio. Sin embargo, esa obligatoria fiscalización por parte del médico de baños a la labor de otros facultativos originaba amplias protestas.

En 1901, el Colegio de Médicos de Gerona había promovido entre los demás Colegios que se reconociese la capacidad de cualquier médico para la administración de aguas minero-medicinales y se declarase la libertad balnearia absoluta ${ }^{55}$. No prosperó la propuesta, pero, cuando en 1911 Ruiz y Valarino, Ministro de Gobernación, presentó el frustrado proyecto de Ley de Bases para la formación de la Ley de Sanidad Civil, las enmiendas para reformar la base decimocuarta (sanidad balnearia), propuestas por Albiñana, mostraban el sentir de un amplio colectivo médico:

$1^{\circ}$ Queda establecida la libertad balnearia en consonancia con las exigencias del progreso y según rige ya en las naciones cultas. 
$2^{\circ}$ Cada propietario de establecimiento balneario podrá colocar al frente de él al profesor médico que tenga por conveniente.

$3^{\circ}$ El Estado ejercerá una inspección sobre dichos establecimientos, para lo cual se creará un Cuerpo de inspectores a base del actual de directores de baños.

Propuestas que, como puede verse, se solapaban con las de los empresarios ${ }^{56}$.

Estos ataques al Cuerpo de Médicos de Baños por parte de otros facultativos vinieron a sumarse a una difícil situación interna:

Rebajados los ingresos de la Sociedad por las deserciones de los resentidos; desiertas las sesiones cientificas por la falta de paz y sobra de bilis; y escasamente posibles las juntas de gobierno; pobre de material el periódico y laboriosísima su aparición por inercia de todos y cada uno de sus proveedores $[\ldots]^{57}$

Estas palabras pertenecían a uno de los miembros del citado tribunal de oposición de Pinilla, Benito Avilés, director en esos momentos de los Anales de la Sociedad Española de Hidrología Médica (y con una antigüedad que le hacía figurar en la primera mitad del escalafón), con las que declaraba la crisis manifiesta de la Sociedad. Los Anales habían suspendido su aparición en 1899 por problemas económicos ${ }^{58}$, el Anuario Oficial de las Aguas Minerales de España sufrió idéntica suerte y la penuria económica les llevó a abandonar sus locales para acogerse en el de la Academia Médico-Quirúrgica ${ }^{59}$. La ciencia hidrológica no era cultivada en general por los médicos de baños y, tan sólo en alguno de sus aspectos, por físicos o químicos. Ante esta situación el Cuerpo de Médicos Directores de Baños perdía prestigio y mostraba su incapacidad de adaptar su esclerosada organización a nuevas situaciones que minaban su existencia, pese a las críticas y autocríticas que clamaban por su regeneración, como la del ya referido Buylla:

En ningún organismo del Estado hay más caciquismo y se siente de modo más directo la influencia egoísta de los santones que en el llamado Cuerpo de Médicos de Baños, y como si en el pecado llevara la penitencia, no hay otro tampoco tan discutido, que viva más á la sordina y que sienta latente el mal de su vida anormal; por esto tiene una Academia y en ella no figuran los más afortunados, es dueño de una Revista y camina anémica, sosa y sin atractivos, á pesar de dirigirla un compañero de dotes especiales y de gran iniciativa. Se confía más en la influencia personal que en la acción colectiva, agradeciendo la existencia al favorito de las alturas y no al derecho que á ella tenemos los que, sacrificándolo todo, figuramos en un escalafón cuyo carácter es el quietismo y que padece de parálisis central ${ }^{60}$

El escalafón suponía que sólo se podía acceder a una buena plaza si se producía el fallecimiento o jubilación de los más veteranos, por lo que los menos pacientes optaron por reclamar la jubilación forzosa previa creación de un montepío. Como reconocía el propio Avilés, refiriéndose a estas jubilaciones: "El último golpe [...] tuvo por resultado acentuar las diferencias que venían dibujándose entre la derecha, ó cabeza, y la izquierda del escalafón del Cuerpo de Médicos-Directores de 
Baños, á consecuencia de determinadas contraposiciones y manifiestas intemperancias [...]",57.

Los grupos a los que aludía tenían nombres propios que representaban esos intereses. Así, la desaparición de los Anales en 1899 dio lugar a que Rosendo Castells y Ballespí, a la zaga del escalafón y republicano y liberal según sus propias palabras $^{61}$, crease la Revista Médico-Hidrológica Española, la que se convertiría en defensora de los intereses de esa "izquierda del escalafón" y, más adelante, de los Médicos Habilitados.

En la cabeza del escalafón se encontraban destacadas figuras que tomaban parte en la vida política del país, entre quienes sobresalía en esta pugna Marcial Taboada de la Riva, miembro permanente del Real Consejo de Sanidad. El papel jugado junto a Avilés en este organismo fue el que consiguió bloquear cualquier intento de establecer una edad para la jubilación obligatoria: nacido en 1837, sus intereses personales prevalecían sobre los del grupo que supuestamente representaba (supuestamente porque, pese a ser por elección entre los médicos de baños, habitualmente lo ostentó por designación) y el Consejo, aunque formado por 40 personas, era coto de una minoría ${ }^{62}$. Por ello, pese a la crisis del Cuerpo, la presencia en el Consejo y el Senado les permitió mantener sus prebendas personales y de la "derecha del escalafón", en un continuo pulso con el resto de los médicos y los empresarios, con el resultado de la pervivencia del Reglamento de Baños de 1874, frustrados proyectos de ley y mínimas y esporádicas reformas que sólo crearon descontento.

Es evidente que los enfrentamientos entre Castells y Taboada fueron frecuentes, especialmente en dos planteamientos: el de las jubilaciones y el de la actitud del Cuerpo hacia los nuevos médicos habilitados ${ }^{63-64}$. Estos últimos reclamaron bien pronto la unificación del escalafón al considerar que ellos también habían obtenido la plaza por oposición y, sin embargo, se encontraban sometidos al criterio de los propietarios, ante quienes debían doblegarse si querían obtener trabajo. De hecho, fueron pocos los empresarios que contrataron médicos habilitados y preferían cubrir las plazas con interinidades impuestas por la administración ${ }^{65}$. Los habilitados no se sintieron identificados con los intereses de la Sociedad y el estilo de los Anales, mientras que la Revista dedicó bien pronto sus páginas a debatir los problemas sociales del nuevo grupo: ya en 1904, recientes aún las primeras oposiciones, Camilo González proponía desde ellas la unificación de Directores y Habilitados ${ }^{66-67}$.

Pese a los patéticos esfuerzos de la cúpula de la Sociedad (mediante circulares y promesas de reducción de cuotas) para que todos los Médicos de Baños, incluidos los habilitados, formasen parte de ella y enviasen colaboraciones a la publicación oficial de la sociedad; éstos se encontraban embarcados en un proyecto diferente de reforma del Cuerpo que se materializó en la organización por parte de Castells y Laureano Lotero, Médico Habilitado, de una Asamblea de Médicos de Baños en diciembre de 1905; criticada agriamente desde los Anales. Fue, sin embargo, en esta Asamblea, donde surgió la primera petición formal de creación de una cátedra de Hidrología Médica. 


\section{La creación de la cátedra}

Rosendo Castells fue uno de los pioneros en reclamar la creación de una cátedra para la enseñanza de la hidrología ${ }^{68}$ reivindicación que culminó al incluir entre los temas de la Asamblea de Médicos de Baños de 1905 el de la enseñanza obligatoria de la Hidrología Médica. La ponencia fue presentada por lsaías Bobo Díez, en la sesión del 19 de diciembre, y tras una discusión, en la que intervinieron también Lotero, Castells, Aleixandre, González Muñoz, Cubells, Llord e Hinojar, se adoptó el acuerdo de "solicitar del Sr. Ministro de Instrucción Pública la creación en todas las Facultades de Medicina de España, de una cátedra de Hidrología médica ó de Terapéutica fisica ${ }{ }^{69-70}$.

Los artículos de Castells y, más tarde, los de Anales $^{71}$ muestran que el reconocimiento universitario no era una aspiración exclusiva de España, sino que contaba con el respaldo de los congresos internacionales de la disciplina. Sin embargo, la instauración de su enseñanza era desigual: precoz en Centroeuropa merced al círculo de Oppolzer, que desde mediados del siglo XIX incentivó la creación de estas cátedras (Winternitz, Benedikt) ${ }^{72}$; no oficial en Italia, con cursos en Padua, Roma, Nápoles o Pavía desde finales de siglo ${ }^{73}$; mientras que en Francia, Toulouse contó con la enseñanza de Garrigou desde 1891, a la que siguieron Bordeaux y Lille, si bien sólo obtuvieron cátedras a partir de 1922. La polémica para la instauración de la enseñanza de la hidrología en París llegó a la Cámara de Diputados y en 1913 se creó un Instituto de Hidrología y Climatología ${ }^{74-75}$. Sin embargo, el planteamiento internacional no se produjo hasta los años 20, a través de la International Society of Medical Hydrology and Climatology ${ }^{76}$.

Desde las páginas de la Revista, Castells continuó la promoción de la cátedra mediante la información de los estudios en otros países ${ }^{77-78-79}$ o una oportuna entrevista al nuevo catedrático de Terapéutica de Madrid, Manuel Márquez, quien realizaba una propuesta idéntica a como tres años más tarde se iba a formular la creación de una cátedra de Hidrología

[...] también la Hidrología Médica tiene derecho para figurar dignamente entre las especialidades de la Medicina y debería ser objeto de una enseñanza especial, que, como la de las restantes especialidades, podría ser, á mi juicio, de perfeccionamiento de los estudios médicos fundamentales y cursarse en el periodo del Doctorado, siendo, además. condición indispensable, tanto para ejercer como Médico libre en los Balnearios, como para tomar parte en oposiciones á las plazas de Médicos del Cuerpo de Baños. Y en cuanto al Profesor de dicha enseñanza, nada más lógico que lo fuese un individuo de este prestigioso Cuerpo, elegido por un tribunal ante el cual demostrase, en oposición pública, [...] las aptitudes docentes de que debe estar adornado todo el que se dedique á enseñar ${ }^{80}$

Efectivamente, un Real Decreto de 5 de enero de 1912 creaba la cátedra de Hidrología Médica como de libre elección entre las del doctorado, siendo Ministro 
de Instrucción Pública, por segunda vez, Amalio Gimeno y Cabañas. Gimeno, polifacético como médico y como político (enseñó las más diversas asignaturas y tuvo a su cargo cinco ministerios diferentes: Instrucción Pública, Marina, Fomento, Estado y Gobernación), era Médico de Baños y ocupaba en esos momentos el tercer lugar en el escalafón y la dirección del balneario de Cestona. Pese a ello, dado su talante liberal y progresista ${ }^{81}$, mostró una mayor sensibilidad que sus compañeros hacia el problema de los Médicos Habilitados, demostrada al presidir la Asamblea de Médicos de Baños y hacerse eco de las propuestas allí efectuadas. De hecho, fue él mismo quien estimuló a los miembros de la Sociedad, durante su sesión de aniversario en 1911, a que le solicitasen la creación de una cátedra, cosa que estos hicieron el 17 de abril del mismo año ${ }^{82}$. Su discurso estuvo impregnado de su ejercicio como patólogo, pues, tras un examen de la ciencia hidrológica en el extranjero, pasó a estudiar la enfermedad que la disciplina padecía en España. Ajeno en este caso a la patología social, su diagnóstico fue atonía del Cuerpo de Médicos de Baños provocada tan solo por causas personales de los componentes del escalafón. Para el tratamiento arrancó "á los presentes solemne promesa de trabajar de veras para fomentar los estudios hidrológicos en nuestro país" ${ }^{33}$.

Solicitado informe a la Facultad de Medicina, el 29 de junio de 1911 su Claustro acordó por unanimidad proponer la creación de la cátedra de Hidrología Médica como de libre elección del doctorado y que debería proveerse por oposición entre doctores de la Facultad de Medicina ${ }^{84}$. Se sumaba con ello a las de Química Biológica, Antropología, Psicología Experimental y Parasitología y Medicina Tropical ${ }^{85}$.

Figura 4 - El Claustro de la Facultad de Medicina solicita la cátedra (AFMUC)

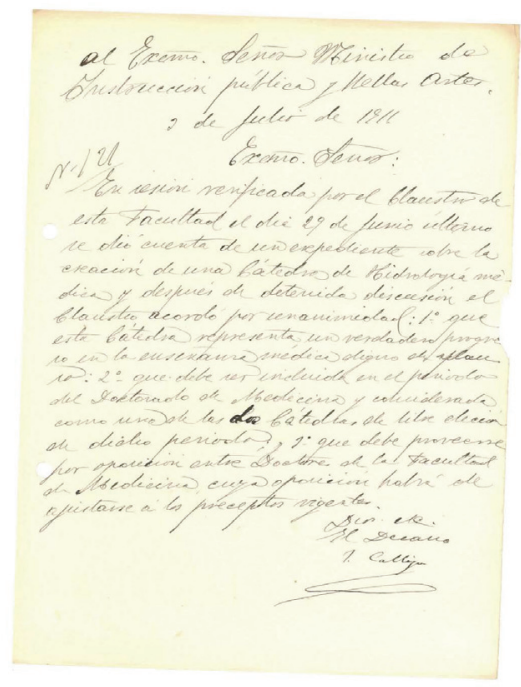


Según Rico-Avello:

La cátedra de Hidrología, también del doctorado, puede tener explicación en la época, dado el desarrollo y actividad balnearia y el prestigio e influencia del Cuerpo de Médicos Directores; ahora bien, nadie negará una oportuna coyuntura, la de encontrarse al frente del Ministerio de Instrucción Pública el doctor Gimeno, número 2 del escalafón, que hizo este milagro en un país donde -al parecer- es tan dificil dotar cátedras ${ }^{86}$

Creo que los presupuestos iniciales de su planteamiento han quedado rebatidos $\mathrm{y}$, aunque es innegable el oportunismo, los motivos de la creación son bastante más complejos. Es sabido que Gimeno fomentó desde su primer Ministerio de Instrucción Pública (en 1906) la relación de docentes e investigadores españoles con otros países europeos a través de las becas de la Junta para Ampliación de Estudios ${ }^{87}$, de las que, según Hernández Díaz, se benefició el propio Pinilla para formarse en Inglaterra y Alemania ${ }^{88}$. En su segundo período ministerial, la Hidrología Médica no fue una excepción y el Bureau Internacional de los congresos de Hidrología eligió Madrid como sede del IX Congreso Internacional y nombró presidente a Gimeno y secretario a Castells. Este congreso, previsto para 1912 pero celebrado finalmente en octubre de 1913, ofrecía el marco ideal para que se hiciesen realidad en España las tendencias internacionales que reclamaban la enseñanza oficial de la disciplina. Castells criticó la coincidencia de congreso y oposiciones pues pensaba que la imagen que habría que dar de la Hidrología española ante las demás naciones en el Congreso influiría en el tribunal para que la plaza no quedase desierta ${ }^{89}$.

El tribunal fue precisamente el principal protagonista de la oposición. La Real Orden de 7 de marzo de 1912 nombraba como presidente a Julián Calleja, el decano de la Facultad de Medicina, y como vocales a Taboada, Alonso Sañudo, Márquez y Manzaneque. Como suplentes se encontraban Martín Salazar, Pinilla, Cerrada y Gurucharri. De éstos, Manzaneque y Pinilla se retiraron pues se presentaban como opositores y Alonso Sañudo renunció por hallarse muy enfermo. Cuando en enero de 1913 se reunió por primera vez el tribunal Alonso Sañudo ya había muerto y el tribunal quedó constituido por Calleja como presidente, Taboada, Martín Salazar y Gurucharri como vocales y Márquez como secretario. Sin embargo, a mayo de 1913 sólo llegaron tres miembros, debido a las muertes de Calleja y Taboada.

De los catorce candidatos que presentaron instancia sólo concursaron cuatro: Hipólito Rodríguez Pinilla y Bartolomé, Enrique Fernández Sanz, Manuel Manzaneque y Adolfo Hinojar y Pons. Pinilla y Manzaneque pertenecían al Cuerpo (y ambos habían representado a España en el Congreso de Clermont-Ferrand), mientras que Fernández Sanz e Hinojar eran habilitados. Tras los ejercicios, las votaciones finales relegaron a Hinojar y los miembros del tribunal repartieron sus apoyos entre los tres restantes: Márquez votó a Fernández Sanz, Gurucharri a Manzaneque y Martín Salazar a Pinilla, aunque en la tercera votación hubo unanimidad en la elección de este último ${ }^{90}$. 
La Hidrología Médica quedaba incorporada como asignatura libre del doctorado, satisfaciendo así los deseos de todos pues se presentó como un vehículo para la recuperación de la industria termal nacional a través de su promoción entre la clase médica. Pero el carácter aislado de la campaña, mostró otras derivaciones: aunque los miembros del Cuerpo de Baños vieron en la cátedra una reafirmación de su existencia como especialidad y un paso decisivo en su institucionalización, también abrió las puertas a sus detractores, que encontraron en su creación el mejor argumento para que todo médico, ahora con posibilidad de adquirir conocimientos hidrológicos refrendados por la Universidad, pudiese enviar a sus pacientes a un balneario. Algo en lo que, como veremos, el criterio y ascenso social de Hipólito Rodríguez Pinilla fueron determinantes.

\section{La cátedra, entre la ciencia hidrológica y el ejercicio profesional}

El 21 de mayo de 1913, Hipólito Rodríguez Pinilla recibió su nombramiento como catedrático numerario de Hidrología Médica de la Facultad de Medicina de la Universidad Central, con el sueldo anual de siete mil pesetas. Sin embargo, la toma de posesión no se produjo en Madrid, sino en Salamanca, pues Pinilla elevó una solicitud al Ministro de Instrucción Pública alegando que, estando tan próximas las vacaciones, el traslado le supondría unos gastos innecesarios. Fue autorizado y, de esta forma, fue ante su amigo Miguel de Unamuno, Rector de la Universidad de Salamanca, como tomó posesión el uno de julio de 1913.

Si hasta ese momento su labor profesional en Salamanca le había permitido permanecer a cierta distancia de los problemas internos del Cuerpo de Médicos de Baños, su traslado a Madrid como catedrático de San Carlos lo convirtió en referente para la hidrología, en lo científico y en lo social.

La enseñanza oficial de la Hidrología gozó bien pronto del favor de los estudiantes: entre las de su categoría, Parasitología e Hidrología eran las asignaturas con mayor número de alumnos ${ }^{2}$. Pinilla en la prolusión del curso 1914-1915 sugería motivos para el éxito de la disciplina: por deseo práctico, sabiendo que iban a tratar con enfermos crónicos; por patriotismo, dada la importancia de las aguas españolas, y por lo estimulante que resultaba la asignatura, llena de temas por investigar ${ }^{91}$. Sólo entre los años 1915 y 1918 se observó una disminución de alumnos, si bien los motivos pueden encontrarse, entre otras explicaciones, por la aparición del proyecto de ley de reforma de las universidades, donde se contemplaba que el Ministro de Instrucción Pública podía suprimir las cátedras sin alumnos o refundir las que entre ambas contasen con un mínimo de cinco: en el intento de evitar que algunas cátedras desapareciesen, se urdieron trampas y transvases de alumnos que no pasaron desapercibidos al periodismo médico de la época ${ }^{92}$.

A partir de los años veinte surgieron también en diversas universidades españolas cátedras de Hidrología, si bien como enseñanza no oficial. Entre ellas hay que destacar la valenciana de Martí Sanchís y la compostelana de Novo Campelo ${ }^{93-94}$. 
Figura 5 - Hipólito Rodríguez Pinilla

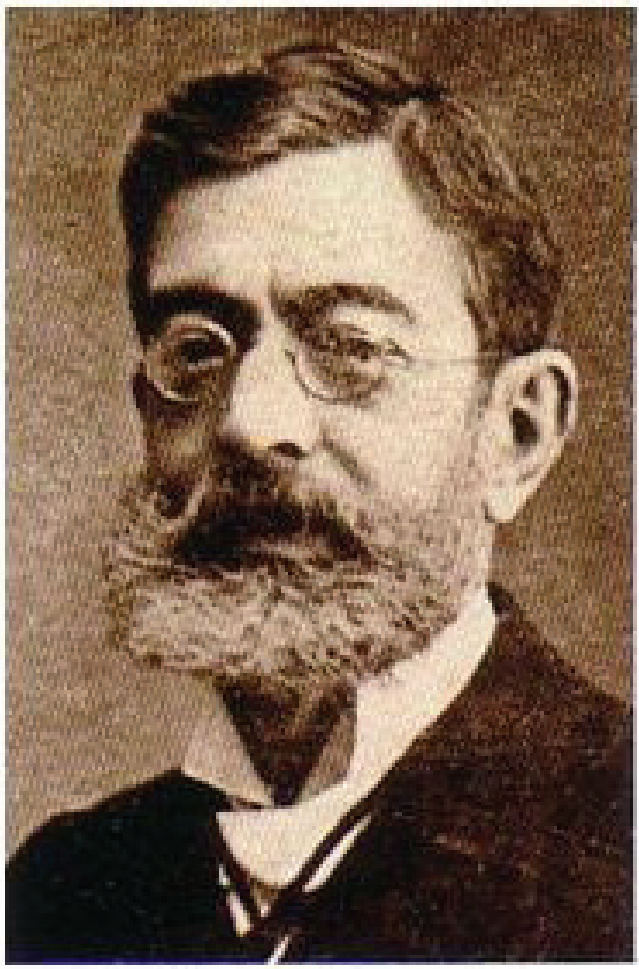

Este éxito de la disciplina podría parecer paradójico por mostrar una clara divergencia con el desinterés social hacia las aguas mineromedicinales, pese a la recuperación del número de agüistas en la década de los veinte, pero que quedará explicada al examinar la legislación.

Desde la cátedra Pinilla emprendió una ambiciosa labor que incluía la creación de escuela (en el sentido de grupo de profesionales por él formados), el desarrollo de investigación, las relaciones internacionales y la divulgación entre los médicos y la sociedad en general de la hidrología médica como recurso terapéutico útil y fundado en unas contrastadas bases científicas.

José García Viñals había nacido en Briviesca (Burgos) en 1890 y el curso 19141915 fue alumno de Pinilla en la asignatura de doctorado, en la que obtuvo matrícula de honor. Bajo su dirección realizó su tesis doctoral sobre "Tratamiento de las enfermedades del aparato respiratorio por las aguas sulfurado cálcicas frías, sulfhídrico-nitrogenadas"95, defendida ante Gómez Ocaña, Simonena, Zúñiga, Fernández Sanz y el propio Pinilla el 24 de marzo de 1916. Cuando en 1919 se convocó el concurso para la plaza de Profesor Auxiliar Temporal de la Cátedra de Hidrología Médica, Viñals lo ganó ${ }^{96}$. A partir de ese momento se convirtió en un discípulo 
idóneo en los proyectos de la cátedra, para los que sus estudios de francés y alemán posibilitaban la comunicación científica internacional. En 1922 era secretario de la sección cuarta, dedicada a la crenoterapia, en el Congreso Internacional de Fisioterapia y Educación Física. El presidente de la sección era, por supuesto, Hipólito Rodríguez Pinilla ${ }^{97}$. Al año siguiente era secretario de la que pretendía ser la primera asamblea anual científica de hidrólogos españoles, en la que también tuviesen cabida todos los médicos, científicos y propietarios de balnearios ${ }^{98}$. Del mismo modo se ocupó de las prácticas en balnearios, de las que han quedado documentadas periodísticamente las de Alhama de Aragón ${ }^{99}$.

El temprano fallecimiento de García Viñals supuso un revés para la cátedra, pero también un revolucionario cambio en la institución. El 24 de junio de 1926 La Gaceta de Madrid publicó la convocatoria de una plaza de Profesor Auxiliar Temporal de Hidrología Médica. La única aspirante fue Antonia Martínez Casado. Nacida en Baena en $1899^{100}$, la unanimidad de la comisión y de la Junta de Facultad la convirtieron en la primera mujer con este cargo en la Facultad de Medicina de San Carlos ${ }^{101}$. Según Hernández Díaz esta incorporación de una mujer al profesorado estaría acorde con el pensamiento de Pinilla, influido tanto en esto como en el funcionamiento del sistema tutorial por lo que había visto durante su estancia de estudios en Cambridge ${ }^{88}$. Aunque ejerció la dirección de algún balneario, Casado no ingresó en el nuevo Cuerpo de Médicos de Aguas Minero-Medicinales hasta $1946^{102}$. Su producción científica sólo permite constatar un Manual de prácticas hidrológicas, escrito junto a Arturo Cervigón Díaz, y que les valió a ambos el Premio Salgado de la Real Academia Nacional de Medicina del año 1933, con el innegable apoyo de Hipólito Rodríguez Pinilla, no sólo por prologarlo, sino por su condición de académico de número desde $1924^{103}$. Desde la jubilación de éste en 1931, Casado asumió el encargo de la cátedra que desempeñó hasta 1943, con el paréntesis de la Guerra Civil y el proceso de depuración, en el que no le impusieron sanción dados los testimonios que aportó de "desafección al régimen rojo", formar parte de los elementos de derechas y denunciar a los más destacados izquierdistas de la Facultad de Medicina. Afortunadamente para Pinilla su fallecimiento evitó que su discípula lo incluyese en la lista ${ }^{104}$.

La investigación de Pinilla abarcó los más diversos aspectos de la ciencia hidrológica, desde los análisis de aguas a los estudios clínicos. Su especialidad pediátrica -sobre la que seguiría dando conferencias y publicando trabajos ${ }^{105}$ - le llevó a una particular línea de investigación sobre las aguas minero-medicinales en las enfermedades de la infancia, algo que compartió con García Viñals. Otra innegable novedad fue la ampliación del objeto de la materia, que si ya se había visto enriquecida por la hidroterapia, con Pinilla incorporaba la climatología, que pasaba incluso a formar parte del nombre de la asignatura de doctorado en $1926^{106}$. Este aspecto no es baladí si nos atenemos al significado socioeconómico de las propuestas: la hidroterapia supuso un reto para el balneario al validar el uso de cualquier agua, fundamentadas sus acciones en la presión y temperatura de aplicación, lo que justificaba 
la competencia del centro hidroterápico urbano; sin embargo, la climatoterapia recuperaba para los balnearios un carácter diferencial que vinculaba los efectos con la cura a pie de manantial. En cualquier caso, los baños de mar también se revalorizaban desde estas perspectivas.

Estas nuevas orientaciones le llevaron a publicar una obra referencial como fue el Manual de Climatología general y española en $1930^{107}$. La labor de sistematización, síntesis y divulgación, emprendida con su Manual de 1902, le llevó a publicar obras de nivel académico como Medicaciones Hidrológicas $(1920)^{108}$ o el Manual de Hidrología Médica de Reus (1925), editorial para la que dirigía la Revista General de Medicina y Cirugía y Bibliotecas Médicas ${ }^{109}$, y nuevas ediciones de su primer manual, editado ahora por Gallach con la incorporación de un glosario hidrológico, lo que acentuaba su función divulgadora. Esta concepción pedagógica y funcional del conocimiento hidrológico produjo también una de sus obras más emblemáticas, el Diccionario General Hidrológico $(1916)^{110}$, que incorporaba un detallado mapa hidrológico de la Península Ibérica y obtuvo el Premio Salgado de la Real Academia Nacional de Medicina en $1918^{103}$.

Su interés por la comunicación internacional, emprendida ya en su época en Salamanca, se plasmaba ahora en congresos y viajes, como el de intercambio de médicos españoles a Burdeos y París en 1923 para dar conferencias ${ }^{111}$. En este sentido, los máximos reconocimientos le vinieron dados al ser elegido miembro de honor de la Sociedad Balneológica de Varsovia y su calidad de representante español en la Sociedad Internacional de Hidrología ${ }^{112}$. Pero el honor mayor fue nacional al ingresar, en sesión celebrada el 20 de enero de 1924, a la Real Academia Nacional de Medicina en el puesto que quedaba vacante en la Sección de Terapéutica por el fallecimiento de José Grinda Forner. Manuel Márquez fue el encargado de contestar a su discurso y, entre sus alabanzas a Pinilla como investigador y como persona, consideraba que había superado el radicalismo de sus preferencias políticas juveniles ${ }^{11}$.

Algo de cierto había en la palabras de Márquez, aunque con una ambigüedad que le permitió proseguir con éxito su carrera durante la dictadura de Primo de Rivera sin perder el contacto con los opositores. Es muy significativa la carta que dirige a Miguel de Unamuno durante el destierro de éste en París, carta que firma como "su miedoso y viejo amigo" y en la que intenta disculparse, explicar lo expresado en otra carta anterior y mostrar que sigue siendo hostil al Directorio:

Al final intentaba dar la explicación de mi pensamiento 'Si puedo servirle de algo...' Si puedo servir $p^{a}$ que ciertas cartas que se abren en el gabinete negro dirigidas a personas significadas vengan por mí (no significado) evitemos que den con el truco.

Que hay cobardía. Indudable. Pero muchos hablarian si hubiese organización. Lo individual es algo estéril ${ }^{113}$

Aunque él mismo se considerase como "no significado" ante el Directorio, el Rector de la Universidad de Oviedo tuvo la precaución de pedir permiso al Director 
General de Instrucción Pública para que Pinilla pudiese dar allí una conferencia en 1928 , obteniendo como respuesta un recordatorio de que las de tipo científico no tenían restricción, pero que si era de otro tipo debía atenerse a la prohibición de propaganda política en Universidades ${ }^{114}$. Otra carta remitida desde Ontaneda a Unamuno, todavía en París, parece mostrar que se mantiene en lucha:

No se si le habran enterado de que yo hice un Manifiesto de protesta contra lo existente que deseaba firmasen catedráticos. No encontré seis. Yo en cambio he suscrito el de los republicanos que llamaré nuevos, y en tal sentido se lo comuniqué a Melquiades ${ }^{115}$

Esta trayectoria política permite comprender que, con la instauración de la Segunda República, Pinilla fuese nombrado Consejero de Estado en noviembre de 1931. Un reconocimiento en un momento de su vida en que, jubilado como catedrático y a punto de estarlo como Médico-Director de Baños, tenía escasas restricciones para poner en funcionamiento cambios radicales en la profesión balnearia.

\section{LA SUPRESIÓN DEL CUERPO DE MÉDICOS DE BAÑOS}

\section{La cuestión médico-balnearia}

Con este término hacía referencia la revista La Información Española, órgano de expresión de los propietarios de establecimientos de aguas minero-medicinales, a la relación entre el Estado, los balnearios y los médicos que querían ejercer en ellos ${ }^{116}$. La concurrencia a los establecimientos balnearios españoles había vivido una relativa recuperación durante la década de los veinte, si bien parecía estabilizarse entorno a una media no superior a los 75.000 bañistas por temporada, cifra que mostraba la radical diferencia en la implantación social del termalismo en España en comparación con Francia o Alemania ${ }^{117-118}$.

Durante la dictadura de Primo de Rivera se produjeron transformaciones radicales en el Cuerpo de Médicos de Baños. El Real Decreto ley de 25-2-1924 creaba el escalafón de Médicos Habilitados, que quedaba unificado al de Médicos Directores por la Real Orden de 27-6-1925, de forma que, a los 32 médicos que integraban el Cuerpo en enero de ese año, se sumaron 94 habilitados, constituyéndose así un cuerpo único con 126 médicos de baños.

Sin embargo, en los restantes aspectos legislativos el Cuerpo seguía rigiéndose por el retocadísimo Reglamento de Baños de 1874 y la no menos alterada Instrucción General de Sanidad de 1904. El 25 de abril de 1928 se aprobaba como Real Decreto Ley un "Estatuto sobre la explotación de manantiales de aguas mineromedicinales", en el que se accedía a la libertad balnearia, condicionada al respeto a los derechos de los médicos del Cuerpo de Baños a los que reservaba, hasta su muerte o jubilación, los balnearios que hasta el momento hubieran estado dirigiendo. Los restantes balnearios constituían un segundo grupo para el que los propieta- 
rios podían contratar al médico que quisieran siempre que tuviese aprobadas las asignaturas de Hidrología Médica y Análisis Químico ${ }^{119}$.

Las críticas y protestas publicadas son, obviamente, bastante cautas y las reformas del Estatuto no complacen ni a hidrólogos, ni a propietarios. Estos últimos fueron reticentes a contratar a estos médicos (como ya sucediera con los habilitados) y se excusaron alegando la gran dificultad en encontrar médicos con esas titulaciones ${ }^{120}$. La Real Orden de 5-6-1929 atajó el problema al encargar a la Dirección General de Sanidad el nombramiento de médicos para aquellos balnearios que no hubiesen contratado a ninguno.

Por su parte, los hidrólogos convocaron en enero de 1930 una Asamblea de Médicos de Baños para "tratar de las posibles peticiones de mejoras". Los antiguos habilitados residentes que se agrupaban en torno a la Revista Médico-Hidrológica Española no sólo se habían integrado, sino que ocupaban en esos momentos cargos en la Sociedad (Castells era vicepresidente primero y Lotero director de los Anales). Sin embargo, las circunstancias políticas llevaron a que Castells expusiese la imposibilidad de derogar el Estatuto y sugiriese la petición de reformas parciales (como el cierre de balnearios clandestinos o la creación de inspecciones balnearias) ${ }^{121}$. Será durante el Gobierno Provisional de la República, siendo Marcelino Pascua Martínez Director General de Sanidad, cuando se obtenga la derogación parcial del Estatuto, perfilada por la ley de 18 de agosto de 1931, por lo que subsistió un año más.

Por su parte los propietarios de balnearios habían intensificado sus acciones en defensa de la "libertad balnearia" y desde 1914 publicaban la citada revista La Información Española (Científica y Comercial). Su primer presidente había sido Juan Madariaga, Conde de Torre-Vélez ${ }^{122}$, al que sucedió Ramón Sáinz de los Terreros. Bajo la presidencia de este último, en enero de 1932, la Asociación remitió una solicitud al Ministro de la Gobernación en la que, aunando sus intereses a los de los médicos generales, manifestaba su principal objetivo:

la consecución de la libertad balnearia, entendiéndose por tal la facultad por parte de los propietarios de elegir los Médicos-Directores de sus establecimientos y, por parte de los que ostentan el título de Doctor o Licenciado en Medicina, la de abrir sus consultas en los Balnearios que tuviesen por conveniente, ejerciendo libremente su profesión sin trabas de ningún género ${ }^{123}$

Pretendía que no se reconociesen las prerrogativas que se habían concedido a los habilitados durante la dictadura (merced a la unificación del Cuerpo) y ampliar la posibilidad de elegir médico, no sólo entre los que tuviesen aprobadas Hidrología Médica y Análisis Químico, sino también entre todos los que hubiesen desempeñado al menos una temporada en un balneario. Pese a ello, respetaba los derechos de los Médicos Directores aún existentes ( 24 y 3 jubilados).

Unos meses más tarde, al celebrar la Junta de Gobierno, Sáinz de los Terreros informaba que: 
Recientemente y a virtud de amplias facultades concedidas al mencionado Ministerio [de la Gobernación] para legislar sobre la industria balnearia, con fecha $1^{\circ}$ del actual [abril] se ha dictado la oportuna orden a virtud de la cual y previo informe de la Dirección general de Sanidad, se concede la más amplia libertad balnearia en cuanto se refiere a la prestación del tratamiento hidromineral, que deberá darse sin refrendo alguno al señalado por cualquier prescripción médica.

Se ha ido más allá de nuestra petición; la libertad concedida es amplia y total, sin mediatización alguna, por lo que debe merecer nuestro más entusiasta aplauso al recoger toda una aspiración y labor de más de cincuenta años $[\ldots]^{124}$

\section{¿Individualismo visionario?: las críticas a Rodríguez Pinilla}

El 31 de marzo de 1932 Niceto Alcalá Zamora autorizaba al Ministro de la Gobernación, Santiago Casares Quiroga, para ocuparse de todos los asuntos referentes a balnearios y provisión de plazas. El primero de abril, Casares dirigía una orden al Director General de Sanidad, Marcelino Pascua, por la que todos los establecimientos de aguas mineromedicinales debían dispensar cualquier tratamiento prescrito por un médico y contemplaba a los Inspectores Provinciales de Sanidad como los únicos responsables de los aspectos higiénicosanitarios y médicoprofesionales en aquellos. Una nueva orden de 16 de mayo ratificaba la anterior y se limitaba a señalar alguna nueva función de los administradores o propietarios ${ }^{125}$.

Los hidrólogos sintieron vulnerados gravemente unos derechos que habían adquirido por oposición y al amparo de la ley, por lo que el cinco de mayo una Asamblea de Médicos de Baños decidía multiplicar sus acciones: una solicitud de audiencia con el Presidente del Consejo de Sanidad, otra de clarificación de la orden en que se hiciese constar que se preservaban los derechos de los miembros del Cuerpo y la consulta a diversos letrados para presentar un recurso contencioso ${ }^{126}$.

Por su parte, los propietarios aplaudían la nueva legislación y sustentaban la necesidad de la libertad por permitir equipararse "en este aspecto a las demás naciones que no supeditan el ejercicio de tal industria a la presión de determinados elementos" y mejorar la "comprensión entre médicos y propietarios, a fin de que estos puedan contar en la dirección facultativa de sus establecimientos a los que científicamente puedan elevar más el crédito y eficacia de esta industria" ${ }^{127}$.

No fueron de ésta opinión los directores de baños quienes dedicaron sus artículos a defender su papel como protectores del enfermo frente a "los excesos, abusos y demasías a que la incultura propia y las codicias de muchos propietarios y administradores [...]" les exponían, como argumentaba Juan de Dios García Ayuso (médico de baños contratado) en El liberal o, asiduamente, en La Medicina lbera ${ }^{128}$. Castells, desde su nuevo cargo de director de los Anales tras la muerte de Lotero, emprendió la elaboración de diferentes escritos: unos, justificativos de la existencia del Cuerpo (comparándolo al de catedráticos, médicos militares o jueces y magis- 
trados) ${ }^{129}$; otros, que mostrasen los desastrosos resultados que estaba produciendo la nueva legislación ${ }^{130-131}, \mathrm{y}$, finalmente, los de carácter informativo sobre la marcha del pleito interpuesto ante el Tribunal Supremo.

El recurso contencioso administrativo fue presentado por los letrados Julio de Saracíbar y Ruperto Aicúa en la sala cuarta del Tribunal Supremo el 17-6-1932. Trece días más tarde se adjuntó uno nuevo firmado por otro grupo de médicos y aún existió un tercero presentado por Gimeno mediante el letrado José Gascón. Tras la reclamación al Ministerio de la Gobernación del expediente que dio lugar al Decreto, Casares Quiroga respondió que no existía, pues había sido acordado en Consejo de Ministros sin consultas previas ${ }^{132}$.

El escrito de demanda constituía un completo estudio de los antecedentes legislativos respecto al Cuerpo y estaba firmado por casi todos los médicos que lo habían formado. Sin embargo, alguna ausencia era particularmente notable y permitía comprender porqué el viejo intento de supresión del cuerpo había logrado en esta ocasión el éxito.

Como hemos visto, el Gobierno Provisional de la República cambió en mayo de 1931 la composición del Consejo de Sanidad. Los médicos del Cuerpo perdían su representatividad, si bien eran nombrados "consejeros a título personal por sus especiales conocimientos científicos" José Sánchez Covisa e Hipólito Rodríguez Pinilla ${ }^{133-134}$.

Pinilla alcanzaba así la cima de su carrera en el mismo año de su jubilación universitaria: Consejero de Estado, primer y único catedrático de Hidrología, académico desde 1924 y presidente de la Sociedad Española de Hidrología Médica, por breves meses, hasta su dimisión en 1930. Los motivos de su dimisión no quedan explicados, pero una carta que dirigió a El Siglo Médico ("no tengo relación profesional [con los médicos de baños] desde que hace un año abandoné la presidencia de la Sociedad Española de Hidrología Médica") ${ }^{135}$ permite suponer que no debió de ser de buen grado, pues seguía estando en activo como médico-director de Caldas de Oviedo. Y, por supuesto, continuaba su labor académica y política. En este último aspecto el salmantino sorprendía a sus antiguos compañeros de Sociedad al presentar ante el Consejo de Sanidad, el 4 de junio de 1932, una ponencia suscrita también por Marañón, Mariscal y Mayoral, para que formase parte del proyecto de la futura ley de sanidad.

Constaba de seis bases, de las que transcribo aquí las más polémicas, la tercera y la última:

Base $3^{a}$. Queda disuelto el actual Cuerpo de Médicos Directores de Baños, y se declara su excedencia forzosa, con el haber de dos quintos de sus emolumentos en las plazas que desempeñan, si los prestaron de diez a veinte temporadas de servicios efectivos; de tres quintos, si desempeñaron el cargo veinte temporadas; y de cuatro quintos, si más de treinta temporadas. [...]

Base $6^{a}$. El Gobierno creará un Instituto de Hidrología y Climatología Médicas con arreglo a las bases que se propusieron por la Comisión oficial nombrada 
por Real orden de 25 de enero de 1925. Dicho Instituto será el plantel de los futuros especialistas o Médicos adscritos al ejercicio profesional de las localidades balnearias ${ }^{136}$

Figura 6 - De izquierda a derecha: Pinilla, Martí Jara, Azaña y Giral (CMU. 93/534)

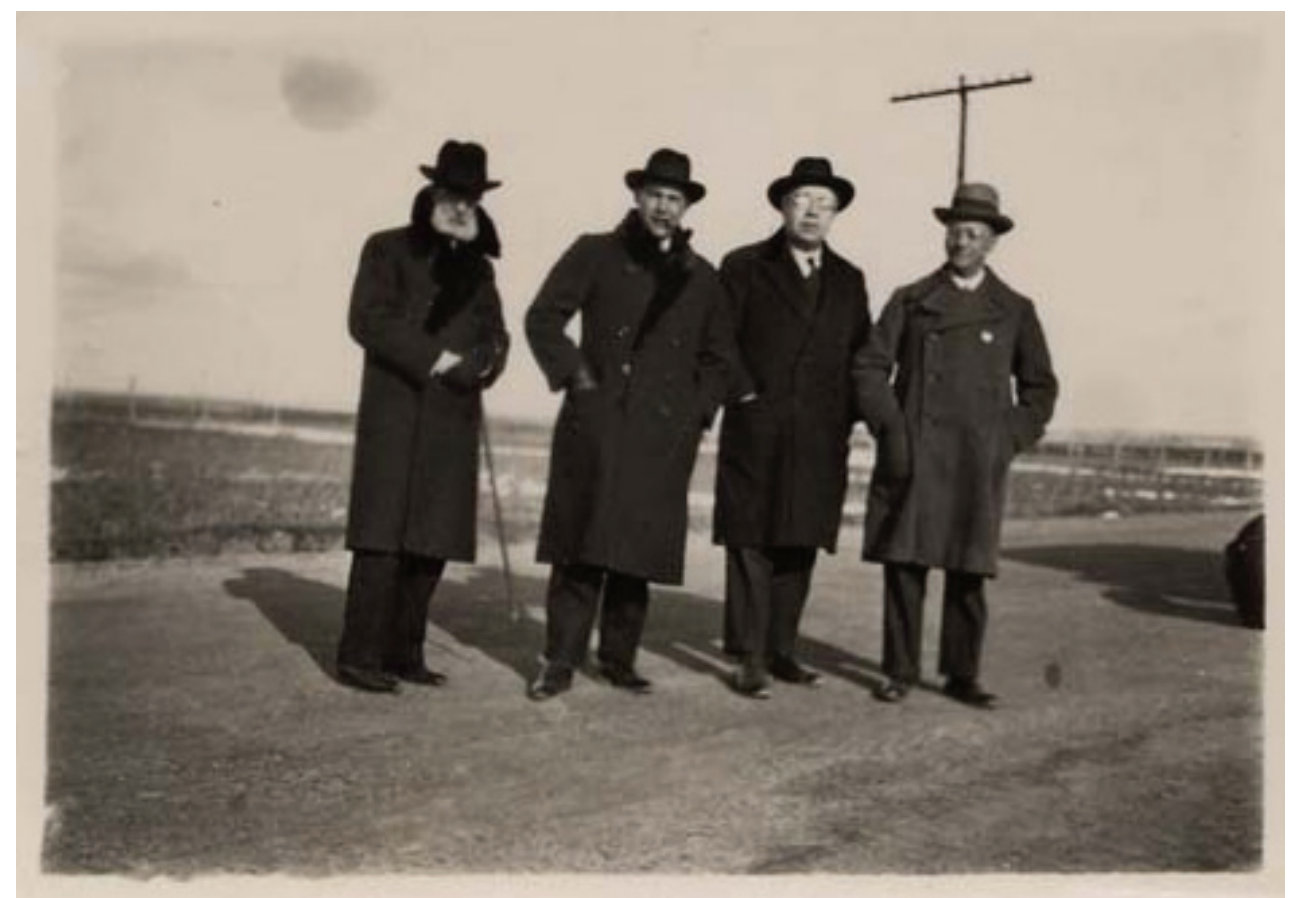

Este último punto era una antigua aspiración que, así matizada, pretendía sentar las bases para la creación de una especialidad hidrológica, reorientada hacia la investigación y desvinculada del pasado del Cuerpo de Médicos de Baños y su deformación administrativa ${ }^{137}$. El mismo año, ante la Academia Nacional de Medicina, Pinilla citaba el ejemplo inspirador:

[...] cuando un amigo mío, visitando el balneario de Wiesbaden, le preguntó a uno de aquellos médicos cuántos enfermos acudian a la localidad, el doctor HARPUDER a quien aludo, le contestó: 'Aqui no nos preocupamos de eso; nos interesa investigar', yo he quedado entusiasmado de la .respuesta y me he dicho que debiéramos imitar a HARPUDER en toda España. Y eso, en España, tiene que hacerse con el empuje del Estado ${ }^{138}$

Tal vez Pinilla actuaba siguiendo una política de hechos consumados, pero su cambio de actitud frente al Cuerpo escandalizó a sus miembros y a la redacción de los Anales. Castells le había dedicado ya varios párrafos ("algunos que no blasonaron de republicanos hasta que la República fué instaurada, se creen hoy en el caso 
de hacer méritos en ella, proponiendo reformas que estiman progresivas, porque, según ellos, existen como vigentes en otras naciones [...]") ${ }^{139}$, pero ahora decide explicar lo que él piensa que son las auténticas motivaciones de Pinilla:

[...] la disolución del Cuerpo de Médico de Baños no la aconsejó ninguna razón suprema de gobierno [...] La proposición aprobada por el Consejo de Sanidad permite atisbar alguna explicación, y discurriendo sobre ella, acaso pueda llegarse a descubrir algunas causas de lo ocurrido. Efectivamente: el Sr. Rodriguez Pinilla, autor de la ponencia, es Médico Director de Baños; tiene setenta y dos años de edad, si no estamos equivocados; subsistiendo el Cuerpo, probablemente sería jubilado, y lo sería con el 50 POR 100 DEL PRODUCTO DE SU PLAZA de Caldas de Oviedo, según la legislación vigente desde 1904; con la ponencia suya, que aprobó el Consejo, se le jubilaría también, pero con el 80 POR 100 DEL PRODUCTO DE SU PLAZA ${ }^{140}$

Parece claro que, aunque la implicación política de Pinilla menguó con los años, el republicanismo siempre formó parte de su ideario. No obstante es preciso tener en cuenta estas últimas acusaciones de Castells pues, al año siguiente de hacerlas, en la Gaceta de 30 de julio de 1933, se publicaba la orden Ministerial de 28 de julio de 1933 por la que se jubilaba a varios médicos-directores, entre ellos a Pinilla quien, tras 46 años en el Cuerpo de Médicos de Baños, desempeñaba en esos momentos la dirección de Caldas de Oviedo.

En 1933 aún se produjeron reformas tendentes a recuperar a los médicos de baños bajo el nombre de Delegados Sanitarios en los Balnearios y dependientes de los Inspectores Provinciales de Sanidad, figuras que con escasos cambios se mantuvieron durante el bienio derechista. La sentencia del Tribunal Supremo se producía el 27 de febrero de 1935 y se declaraba incompetente frente al decreto, pero no así ante las órdenes, que declaraba nulas, por lo que se volvía en casi todos sus aspectos al Estatuto de la dictadura y a un nuevo concurso para cubrir las plazas balnearias, mediada ya la temporada de 1935. Sin embargo, los elementos institucionales representativos de los médicos de baños no pudieron recuperarse con igual facilidad: desde diciembre de 1932 había suspendido sus sesiones la Sociedad Española de Hidrología Médica y dejaron de publicarse los Anales, que ya sólo aparecerían en mayo de 1935 y en abril de 1936.

Sin descartar los motivos particulares presentes y la innegable influencia de Pinilla como Consejero de Estado y de Sanidad (cargo del que dimitió "por un acto de delicadeza" ${ }^{141}$, con sus ideas de reconversión del hidrólogo en investigador, es necesario considerar otros factores que influyeron en la supresión del Cuerpo de Médicos de Baños. Las órdenes que plantearon el pleito y la aprobación sin discusión de la ponencia de Pinilla en el Consejo de Sanidad, muestran que la clase médica era favorable a la desaparición de un cuerpo que simbolizaba, por sus prebendas, a una aristocracia sanitaria. No había sido el primer ataque a su caduca organización, pero en esta ocasión las tendencias políticas en el gobierno no favorecían su perpetuación. Sin que consten manifestaciones expresas, el control estatal 
centralizado de la industria termal representado por el Cuerpo de Médicos de Baños no podía ser visto con agrado por un autonomista como Casares Quiroga, máximo dirigente de la ORGA (Organización Regional Gallega Autónoma); cuestión que sí fue planteada claramente en Cataluña, tras el traspaso de las competencias sanitarias, con la desvinculación de sus balnearios de los dependientes del Cuerpo.

Mucho más decisiva, sin embargo, fue la nueva visión del balneario que había de tomar forma a lo largo del siglo. Pinilla publicó en la Gaceta Médica Española un artículo, que también reprodujo La Información Española, en el que presentaba el turismo y termalismo como industria, su estado en el extranjero y apuntaba la discusión:

[...] no falta quien piensa que el termalismo debe entrar a formar parte en las oficinas del turismo, oficialmente organizado.

Contra tal tendencia u opinión levantarán su protesta buen golpe de médicos, y mayor de enfermos, en agobio por crónicas dolencias.

Mas en lo que parece que debe imperar un acuerdo, es en que turismo y termalismo son dos fuentes de riqueza y de buenos apoyos en las economías nacionales. ${ }^{142}$

Entre médicos detractores ${ }^{143}$ y entusiastas propietarios se pergeñaba una nueva concepción del balneario, materializada en la progresiva cooperación entre la Asociación Nacional de la Propiedad Balnearia y el Patronato de Turismo, que implacablemente había de trasladar a los bañistas a la institución hostelera ${ }^{144}$.

La salud de Hipólito Rodríguez Pinilla nunca había sido buena, aquejado por frecuentes problemas respiratorios y por una depresión (acentuada tras la muerte de un hijo en 1925) a la que hacía referencia como "acedia" y cuyo significado histórico indagó junto a su amigo Unamuno ${ }^{145}$. Su fallecimiento en Madrid a causa de un proceso cardiaco, el 29 de marzo de 1936, suscitó escasas reacciones: Unamuno lo recordó en un periódico local como un hombre bueno heredero del espíritu paterno del 68 y como persona apegada a su tierra, lo que le había llevado a fundar la Casa Charra en Madrid ${ }^{146}$, la única de la que encontramos constancia de que le tributase un homenaje, en el que no figuraron médicos de baños, hidrólogos ni discípulos ${ }^{147}$. Aunque la muerte le liberó de presenciar mayores tragedias, sus últimos años hubo de vivirlos como "un enemigo del pueblo" a ojos de los profesionales que hasta esas fechas lo habían considerado como el máximo representante de la Hidrología Médica en España y artífice de su plena institucionalización. La perspectiva histórica muestra que su figura fue rica en matices, ampliados por el momento histórico, los escenarios y las actividades concretas en que estuvo inmerso. Entre la ideología y los intereses personales, entre el corporativismo y la percepción de la necesidad de cambio, entre la ciencia y la industria, entre el conservadurismo del paradigma y la apertura necesaria para la investigación, la labor de Hipólito Rodríguez Pinilla fue probablemente el hito más importante de la Hidrología Médica en España. 


\section{BIBLIOGRAFÍA}

1. Rodríguez Sánchez, JA. La creación de la Cátedra de Hidrología Médica (1912). In: Castellanos Guerrero, J; Jiménez Lucena, I; Ruíz Somavilla, MJ; Gardeta Sabater, P (coord.) La medicina en el siglo XX. Estudios Históricos sobre Medicina, Sociedad y Estado. Málaga: Sociedad Española de Historia de la Medicina, 1998, pp. 201-212.

2. Rodríguez Sánchez, JA. La supresión del Cuerpo de Médicos de Baños (19321936). In: Castellanos Guerrero, J; Jiménez Lucena, I; Ruíz Somavilla, MJ; Gardeta Sabater, P (coord.) La medicina en el siglo XX. Estudios Históricos sobre Medicina, Sociedad y Estado. Málaga: Sociedad Española de Historia de la Medicina, 1998, pp. 269-280.

3. Casa Museo Unamuno (CMU). Fondo Correspondencia. Signatura 59/2-37.

4. CMU. Correspondencia. 38/37, 24.

5. Archivo Diocesano de Salamanca. Signatura 433/10. Parroquia de Santa María de los Caballeros. Libro de bautismos (1852-1872), f. 78-78v.

6. Archivo General de la Administración (AGA). (1)10.5. Caja 21316. Expediente de clasificación de pensión de viudedad y orfandad del funcionario Tomás Rodríguez Pinilla.

7. Entrada "Rodríguez Pinilla (Tomás)". Enciclopedia Universal Ilustrada Europeo-Americana (Espasa), 1926, 51:1311.

8. Un hombre de antaño. Tomás Rodríguez Pinilla (1814-1886). Remembranza. Salamanca: Imprenta y Librería de Francisco Núñez Izquierdo, 1926.

9. Rodríguez Pinilla, H. "Los hombres del 68". In: Un hombre de antaño. Tomás Rodríguez Pinilla (1814-1886). Remembranza. Salamanca: Imprenta y Librería de Francisco Núñez Izquierdo, 1926, pp. 5-10.

10. Martínez Reguera; L. Bibliografía Hidrológico-Médica Española. Manuscritos y Biografías. Madrid: Tip. Sucesores de Rivadeneyra, 1897, tomo II, pp. 828829.

11. Sánchez Granjel, L. "Rodríguez Pinilla, 'Republicano histórico"”. Boletín de la Real Academia Nacional de Medicina [Segunda Época], 2012, 8:23.

12. Entrada "Rodríguez Pinilla (Hipólito)". Enciclopedia Universal Ilustrada Europeo-Americana (Espasa), 1926, 51:1310-1, p. 1311.

13. El Criterio Médico, 1883, 24 (30 Nov): 505-509.

14. El Criterio Médico, 1888, 29 (1): 7-8.

15. El Criterio Médico, 1887, 28 (11): 321-327.

16. El Criterio Médico, 1888, 29 (3): 65-69.

17. Álvarez-Sierra, J. Diccionario de autoridades médicas. Madrid. Editora nacional, 1963, p. 463.

18. Granjel, LS. La Facultad Libre de Medicina de Salamanca (1868-1903). Salamanca: Centro de Estudios Salmantinos, 1989. 
19. Carreras Panchón, A. "La Medicina, siglos XVI-XIX". In: Rodríguez-San Pedro Bezares, Luis E. (coord.) Historia de la Universidad de Salamanca. Salamanca: Ediciones Universidad de Salamanca, 2002-2009, III(1):303-344, p. 323.

20. Blanco Prieto, F. Confidencias de Unamuno a su médico de cabecera. Cuadernos de la Cátedra Miguel de Unamuno, 2008, 46(2):105-158, pp. 121, 131 y 150 .

21. Esteban de Vega, M, González Gómez, S, Redero San Román, M. Salamanca, 1900-1936: la transformación limitada de una ciudad. Salamanca: Diputación provincial, 1992.

22. Archivo Histórico de la Universidad de Salamanca. Serie: Expedientes de Profesorado. Signatura: AC 1341/1. Expediente del Profesor de Patología Médica D. Hipólito Rodríguez Bartolomé.

23. Morales, JL. El niño en la cultura española. Madrid: s.e., 1960, tomo I, pp. 357-358.

24. Carreras Panchón, A. La Medicina en el siglo XX. In: Rodríguez-San Pedro Bezares, LE (coord.) Historia de la Universidad de Salamanca. Salamanca: Ediciones Universidad de Salamanca, 2002-2009, III(1):389-406, p. 389.

25. Archivo General de la Administración (AGA). (5)22 32/16098. Expediente personal del Catedrático de la facultad de medicina. Rodriguez Pinilla y Bartolomé (D. Hipólito).

26. Matilla, V. 202 biografías académicas. Madrid: Real Academia Nacional de Medicina, 1987, pp. 190-192.

27. Revista Médico-Hidrológica Española, 1906, 7:195.

28. Sánchez Granjel, L. El doctor Villalobos y la introducción de la Radiología en Salamanca. In: Robledo Hernández, Ricardo (coord.) Sueños de concordia. Filiberto Villalobos y su tiempo histórico, 1900-1955. Salamanca, Caja Duero, 2004, pp. 107-122.

29. CMU. Correspondencia. 38/37, 14.

30. Archivo Histórico de la Universidad de Salamanca. Actas de claustros y Juntas de la Universidad. Libro 1882 -1907 (AUSA 545) y libro 1907-1920 (AUSA 546).

31. García García, JM. Prensa y vida cotidiana en Salamanca (siglo XIX): Aproximación a la historia del periodismo salmantino. Salamanca, Ediciones Universidad de Salamanca, 1990, p 137.

32. García García, JM. Prensa y vida cotidiana en Salamanca (siglo XIX): Aproximación a la historia del periodismo salmantino. Salamanca, Ediciones Universidad de Salamanca, 1990, p. 191.

33. Rabaté, JC. Filiberto Villalobos y La Unión Escolar. In: Robledo Hernández, $\mathrm{R}$ (coord.) Sueños de concordia. Filiberto Villalobos y su tiempo histórico, 1900-1955. Salamanca, Caja Duero, 2004, pp. 87-105, p. 88. 
34. Blanco Prieto, F. Vecinos ilustres de Salamanca. Salamanca, Globalia Ediciones Anthema, 2008, p. 222.

35. Rodríguez de las Heras, A. Filiberto Villalobos. Su obra social y política (1900-1936). Salamanca, Caja Duero, 2005 (2 ed), pp. 86-87.

36. Suárez Cortina, M. El Partido Reformista y la política española del primer tercio del siglo XX. In: Robledo Hernández, R (coord.) Sueños de concordia. Filiberto Villalobos y su tiempo histórico, 1900-1955. Salamanca, Caja Duero, 2004, pp. 157-179, p. 166.

37. Villacorta Baños, F. Profesionales y burócratas. Estado y poder corporativo en la España del siglo XX, 1890-1923. Madrid: Siglo XXI, 1989, pp. 69-71.

38. Maraver Eyzaguirre, F. L'hydrologie médicale dans l'Espagne de "La Restauration" 1874 -1902. Presse Thermale et Climatique. 2007, 144:151-163.

39. CMU. Correspondencia. 38/37, 10.

40. Rodríguez Pinilla, H. Manual de Hidrología Médica. Barcelona: Manuel Soler [1902-1903] (Manuales Soler, 28)

41. AGA Gobernación, Caja 139/1 (Top. 44/1)

42. Rodríguez Sánchez, JA. José Salgado y Guillermo (1811-1890) y la madurez de la Hidrología Médica española. Medicina e Historia (Tercera Época), 1993, 49, pp. 9-10.

43. El Imparcial, 19-1-1899 y 26-1-1899.

44. Rodríguez Sánchez, JA. Agua que aún mueve molino: metodología de la investigación en historia de la hidrología. Anales de Hidrología Médica, 2007, 2:9-26.

45. Castells Ballespí, R. La verdad de las estadísticas. Revista MédicoHidrológica Española, 1901, 2:140-141.

46. Castells Ballespí, R. El Congreso de Grenoble. Revista Médico-Hidrológica Española, 1902, 3:249-252.

47. Lotero Fernández, L. Balnearios y bañistas clandestinos. Revista MédicoHidrológica Española, 1907, 8:147-151.

48. Lotero Fernández, L. La disminución de concurrencia balnearia en algunos establecimientos. Revista Médico-Hidrológica Española, 1907, 8:217-220.

49. Luis Gómez, A (dir). Aproximación histórica al estudio de los balnearios montañeses (1826-1936). Santander, Cámara Oficial de Comercio, Industria y Navegación de Cantabria, 1989.

50. San Pedro Martínez, $M^{\mathrm{a} A}$. El balneario de Puente Viesgo (1796-1936): el turismo balneario de interior en Cantabria: génesis, esplendor y decadencia de un espacio de ocio. Santander, Universidad de Cantabria - Fundación Marcelino Botín, 1993.

51. Buylla, A. Hay que hacer mucho y pronto. Revista Médico-Hidrológica Española, 1904, 5:12-15, p. 14.

52. La libertad balnearia: Contienda entre Propietarios y Médicos-Directores de Balnearios. Madrid. Establ. Tipográfico de Jaime Ratés, 1910. 
53. Rodríguez Sánchez, JA. Institucionalización de la Hidrología Médica en España. In: Maraver Eyzaguirre, F (coord.) Establecimientos balnearios: historia, literatura y medicina. Madrid: Universidad Complutense de Madrid, 2006, pp. 25-40.

54. Buylla, A. Hay que hacer mucho y pronto. Revista Médico-Hidrológica Española, 1904, 5:12-15, p. 13.

55. Castells, R. Funciones de los Colegios. Revista Médico-Hidrológica Española, 1901, 2:118-121.

56. Sobre el proyecto de Ley de Sanidad. El Siglo Médico. 1911, 58:361-362, p. 362.

57. Avilés, B. Crónica. Anales de la Sociedad Española de Hidrología Médica, 1903, 15:26-28, p. 26.

58. Anales de la Sociedad Española de Hidrología Médica, 1899, 15:93.

59. Noticias. Anales de la Sociedad Española de Hidrología Médica, 1903, 15:24.

60. Buylla, A. Hay que hacer mucho y pronto. Revista Médico-Hidrológica Española, 1904, 5:12-15, p. 12.

61. Dr. Cauterio Rojo [Rosendo Castells]. Más sobre la plaza de Médico de la Comisión mixta. Revista Médico-Hidrológica Española, 1915, 16:99-100.

62. Rico-Avello, C. Historia de la Sanidad Española (1900-1925). Madrid, s.ed., 1969, p. 27.

63. Castells, R. Las jubilaciones. Revista Médico-Hidrológica Española, 1903, 4:35-43.

64. Castells, R. El banquete. Revista Médico-Hidrológica Española, 1904, 5:9397.

65. Un Médico de Aguas Minerales Habilitado. Justa defensa. Revista MédicoHidrológica Española. 1904, 5:358-9.

66. González, C. A los Médicos Habilitados de Baños. Revista MédicoHidrológica Española. 1904, 5:379-81.

67. Cilleruelo, C. ¡Qué decepción!. Revista Médico-Hidrológica Española. 1905, 6:95-98.

68. Castells, R. Nuevas asignaturas. Revista Médico-Hidrológica Española. 1902, 3:222-223.

69. Castells, R. La Asamblea de Médicos de Baños. Revista Médico-Hidrológica Española. 1905, 6:401-412, pp. 407-408.

70. Bobo Díez, I. Necesidad de la enseñanza obligatoria de la Hidrología Médica. Revista Médico-Hidrológica Española. 1906, 7:319-322.

71. La Cátedra de Hidrología en la Cámara de Diputados. Anales de la Sociedad Española de Hidrología Médica. 1911, 23:100-109.

72. Lesky, E. The Vienna medical School of the 19th Century. Jerusalem. The Johns Hopkins University Press, 1976, pp. 125-127, 300-303.

73. Rodríguez Sánchez, JA. Luigi Chiminelli: la institucionalización de la Hidrología italiana a finales del siglo XIX. In: Carrillo, JL; Olagüe de Ros, G 
(eds.). Actas del XXXIII Congreso Internacional de Historia de la Medicina (Granada, 1-6-IX-1992). Granada-Sevilla, 1994, pp. 1169-1176.

74. Wallon, A. La vie quotidienne dans les villes d'eaux (1850-1914). Paris, Hachette, 1981, pp. 125-126.

75. Carribon, C. Thermalisme et corps medical en France, 1919-1939. In: Villes d'Eaux: Histoire du Thermalisme (Actes du 117e Congrés National des Sociétès Savantes, Clermont-Ferrand, octubre 1992). Paris, CTHS, 1994, pp. 135-146, pp. 135-138.

76. Messini, M. History of the International Society of Medical Hydrology and Climatology (1922-1966). Pisa, Nistri-Lischi, 1966, pp. 52-65.

77. Fasano, A. Importancia de la enseñanza oficial de la Hidrología y de la Fisicoterapia y necesidad de la fundación de sus cátedras universitarias. Revista Médico-Hidrológica Española. 1906, 7:181-188.

78. Viaje de estudios médicos a los establecimientos hidrominerales de Italia. Revista Médico-Hidrológica Española. 1910, 11:156.

79. Viaje de estudios médicos á los establecimientos hidrominerales de Francia. Revista Médico-Hidrológica Española. 1910, 11:156-157.

80. Marquez, M. Breves consideraciones acerca de la cura hidromineral y su enseñanza. Revista Médico-Hidrológica Española, 1909, 10:356-357.

81. Granjel, L. Historia política de la medicina española. Salamanca, Instituto de Historia de la Medicina Española - Real Academia de Medicina de Salamanca, 1985, pp. 100-103.

82. AGA, (5)19.1 32/07554.

83. La Redacción. La Sociedad Española de Hidrología Médica y el Cuerpo de Médicos de Baños. Revista Médico-Hidrológica Española. 1911, 12:85-87, p. 85 .

84. Archivo General Facultad de Medicina de la Universidad Complutense. Carpeta Dotaciones de cátedras. Creación de la Cátedra de Hidrología Médica. 1911.

85. García del Carrizo, G. Historia de la Facultad de Medicina de Madrid (18431931). Tesis. Madrid: Universidad Central, 1963, p. 439.

86. Rico-Avello, C. Historia de la Sanidad Española (1900-1925). Madrid, s.ed., 1969, p. 204.

87. Sánchez Ron, JM. La Junta para Ampliación de Estudios e Investigaciones Científicas ochenta años después. In: Sánchez Ron, JM (coord.) 1907-1987. La Junta para Ampliación de Estudios e Investigaciones Científicas ochenta años después. Madrid, CSIC, 1988, I:1-61.

88. Hernández Díaz, JMa . Entre las resistencias al cambio y la Universidad deseada, 1900-1936. In: Rodríguez-San Pedro Bezares, LE (coord.) Historia de la Universidad de Salamanca. Salamanca: Ediciones Universidad de Salamanca, 2002-2009, I:283-312, p. 311. 
89. Dr. Cauterio Rojo [Rosendo Castells]. La cátedra de Hidrología Médica. Revista Médico-Hidrológica Española. 1912, 13:290.

90. AGA, (5)19.1 32/07554.

91. Rodríguez Pinilla, H. Cátedra de Hidrología Médica. Prolusión al curso de 1914-1915. Anales de la Sociedad Española de Hidrología Médica. 1914, 25:133-136, 155-158.

92. Decio Carlan [La Redacción]. Boletín de la semana. Cátedras sin alumnos. El Siglo Médico. 1912, 59:844-845.

93. Ecos y noticias. Anales de la Sociedad Española de Hidrología Médica. 1929, 37:199.

94. Lotero, L. Crónica. Anales de la Sociedad Española de Hidrología Médica. 1930, 38:5-12, pp. 9-12.

95. Archivo de la Biblioteca de la Facultad de Medicina de la Universidad Complutense. Fo 2059(4).

96. AGA, Educación, Caja 15817, Leg 614/50 (Top 31/17)

97. Congreso Internacional de Fisioterapia y Educación Física. ABC, 13-8-1922, p. 31.

98. Congreso de Hidrología Médica. ABC, 14-12-1923, p. 20.

99. Los alumnos del Doctorado de Medicina. ABC, 17-5-1921, p. 9.

100. AGA, Educación, Serie Cátedras de Universidad, Caja 1488/4 (Top 31/35)

101. García del Carrizo, G. Historia de la Facultad de Medicina de Madrid (18431931). Tesis. Madrid: Universidad Central, 1963, p. 927.

102. Rodríguez Sánchez, JA. Ámbitos de poder de la Hidrología Médica española durante el franquismo. Estudos do Século XX, 2005, 5:159-177, pp. 168-170.

103. Rodríguez Sánchez, JA. José Salgado y Guillermo: el Premio en la Historia. Boletín de la Sociedad Española de Hidrología Médica (cuarta Época), 1994, 9:105-111.

104. AGA, Educación, Leg. 9953/29 (Top 32/37)

105. Morales, JL. El niño en la cultura española. Madrid: s.e., 1960, tomo III, pp. 666-668.

106. Archivo General Facultad de Medicina de la Universidad Complutense. Oficio del Director General de Enseñanza Superior en que comunica el cambio de nombre de la asignatura Hidrología Médica. 1926.

107. Rodríguez Pinilla, H. Manual de climatología general y española. Madrid: J. Cosano, 1930.

108. Rodríguez Pinilla, H. Medicaciones hidrológicas. Madrid: Saturnino Calleja, 1920.

109. ABC, 28-8-1925, p. 8 .

110. Rodríguez Pinilla, H. Diccionario General Hidrológico. Comprendiendo términos de Físico-Química y Geología. Madrid: Imp. Julio Cosano, 1916.

111. Médicos españoles a Francia. ABC, 28-4-1923, p. 14. 
112. Entrada "Rodríguez Pinilla (Hipólito)". Enciclopedia Universal Ilustrada Europeo-Americana (Espasa), Apéndices, 1933, 9:353.

113. CMU. Correspondencia. 38/37, 24.

114. AGA, (5)22 32/16098. Expediente personal del Catedrático de la facultad de medicina. Rodriguez Pinilla y Bartolomé (D. Hipólito).

115. CMU. Correspondencia. 38/37, 25.

116. La cuestión Médico Balnearia. La Información Española (Científica y Comercial). 1934, 19(212):1.

117. Rodríguez Pinilla, H. Turismo y termalismo. La Información Española (Científica y Comercial). 1932, 17(189):1-2.

118. Castells, R. El régimen balneario en algunos países. Anales de la Sociedad Española de Hidrología Médica. 1932, 39:25-6.

119. Estatuto sobre la explotación de manantiales de aguas minero-medicinales. Anales de la Sociedad Española de Hidrología Médica. 1928, 37:44-68, p. 47.

120. La asistencia médica en los balnearios. Anales de la Sociedad Española de Hidrología Médica. 1929, 37:257-9.

121. Lotero, L. Crónica. Anales de la Sociedad Española de Hidrología Médica. 1930, 38:5-12, p. 10.

122. Esperabé de Arteaga, E. Diccionario enciclopédico ilustrado y crítico de los Hombres de España. Madrid, Gráficas Ibarra, 1956.

123. Crónica. Anales de la Sociedad Española de Hidrología Médica. 1932, 39:410 , pp. 4-5.

124. Asociación Nacional de la Propiedad Balnearia. Junta General. La Información Española (Científica y Comercial). 1932, 17(188):1-3, p. 2.

125. Anales de la Sociedad Española de Hidrología Médica. 1932, 39:78-79.

126. La Redacción. La Asamblea del Cuerpo de Baños. Anales de la Sociedad Española de Hidrología Médica. 1932, 39:34-37.

127. La libertad balnearia. Una disposición de gran interés. La Información Española (Científica y Comercial). 1932, 17(188):3.

128. García Ayuso, JdeD. Sobre la cuestión balnearia. Anales de la Sociedad Española de Hidrología Médica. 1932, 39:41-44, p. 41 (tomado de El Liberal).

129. Castells, R. El nuevo régimen balneario. Anales de la Sociedad Española de Hidrología Médica. 1932, 39:37-8.

130. Castells, R. Consecuencia de las famosas disposiciones dictadas en abril y mayo contra el Cuerpo de Médicos-Directores de Baños". Anales de la Sociedad Española de Hidrología Médica. 1932, 39:114-5.

131. Castells, R. El fracaso de las disposiciones últimas sobre establecimientos balnearios. Anales de la Sociedad Española de Hidrología Médica. 1932, 39:207-11.

132. Castells, R. El pleito de los Médicos de Baños. Anales de la Sociedad Española de Hidrología Médica. 1932, 39:113-5. 
133. Ecos y noticias. Anales de la Sociedad Española de Hidrología Médica. 1931, 38:303-4.

134. Muñoz Machado, S. La sanidad pública en España (Evolución histórica y situación actual). Madrid: Instituto de Estudios Administrativos, 1975, pp. 105-6.

135. Una carta interesante del Dr. Rodríguez Pinilla. El Siglo Médico. 1932, 89:312.

136. Castells, R. Un acuerdo del Consejo de Sanidad. Anales de la Sociedad Española de Hidrología Médica. 1932, 39:90-3, pp. 90-1.

137. Archivo de la Real Academia Nacional de Medicina. Actas de Sesiones de Gobierno. Tomo 20. Junta de gobierno de 18 de noviembre de 1932, f. 29v.

138. Rodríguez Pinilla, H. Sobre la conveniencia de crear el Instituto Español de Hidrología y Climatología. Anales de la Academia Nacional de Medicina (Segunda época). 1932, 3:499-505 y 509-517, pp. 500-1.

139. Castells, R. El régimen balneario en algunos países. Anales de la Sociedad Española de Hidrología Médica. 1932, 39:25-6, p. 25.

140. Castells, R. Un acuerdo del Consejo de Sanidad. Anales de la Sociedad Española de Hidrología Médica. 1932, 39:90-3, p. 92.

141. La Información Española (Científica y Comercial), 1934, 19(211):3.

142. Rodríguez Pinilla, H. Turismo y termalismo. La Información Española (Científica y Comercial). 1932, 17(189):1-2, p. 1.

143. García Ayuso, J de D. La intervención de la Sanidad oficial en la explotación de los balnearios. La Medicina Ibera. 1934, CLXVII-CLXIX, p. CLXIX.

144. Los Balnearios y el Turismo. La Información Española (Científica y Comercial). 1935, 20(222):1-2.

145. CMU. Correspondencia. 38/37, 32.

146. Al recibir, por telegrama, la noticia de la muerte de Don Hipólito Rodríguez Pinilla. El Adelanto, 31-3-1936.

147. Homenaje a la memoria del doctor Rodríguez Pinilla. ABC, 16-5-1936, p. 39. 